\title{
The Impact of Armed Conflict on Economic Performance: Evidence from Rwanda
}

\section{Pieter Serneels' and Marijke Verpoorten ${ }^{2}$}

\begin{abstract}
Important gaps remain in the understanding of the economic consequences of civil war. Focusing on the conflict in Rwanda in the early 90s, and using micro data, this article finds that households and localities that experienced more intense conflict are lagging behind in terms of consumption six years after the conflict, a finding that is robust to taking into account the endogeneity of violence. Significantly different returns to land and labor are observed between zones that experienced low- and high-intensity conflict which is consistent with the ongoing recovery. Distinguishing between civil war and genocide, the findings also provide evidence that these returns, and by implication the process of recovery, depend on the form of violence.
\end{abstract}

\section{Keywords}

civil war, economic growth, Rwanda, human capital

\section{Introduction}

Civil conflict remains important in many developing countries and has become an integral part of the study of economic development. Especially the last decade has seen a boom in research in this field. ${ }^{1}$ One finding that stands out is the strong

\footnotetext{
' University of East Anglia, Norwich Research Park, Norwich, UK

${ }^{2}$ IOB-University of Antwerp, Antwerp, Belgium

\section{Corresponding Author:}

Marijke Verpoorten, IOB-University of Antwerp, Prinsstraat I3, Antwerp, B-2000, Belgium.

Email: marijke.verpoorten@uantwerpen.be
} 
negative association between conflict and economic development. However, while conflict may lead to poor economic performance, the reverse relationship seems equally credible, and this complicates the analysis. ${ }^{2}$ Moreover, very little is known about the microeconomic mechanisms underlying postwar recovery (or lack thereof).

This article addresses both these issues. Focusing on Rwanda, it investigates whether conflict has a sustained effect on microeconomic performance in the years immediately after the conflict, taking endogeneity into account, while also examining the underlying processes. Part of a small and growing literature on subnational analysis of conflict, the article complements existing work in several ways: by focusing on within country analysis, comparing the effects of different types of violence, and by examining the underlying microeconomic processes of recovery.

From an economic theoretical perspective, there is no consensus about the impact of conflict on economic performance. Neoclassical growth theory predicts that an economy recovers relatively quickly and converges to its steady state. Alternative models argue that catch-up may take a long time, for instance, because human capital recovers only slowly (see Barro and Sala-i-Martin 2004) or that countries can be trapped in a low-level equilibrium where conflict and poor performance coexist (Sachs 2005). Current evidence, relying on cross-country data, provides support for either of these views, with some work finding evidence for relatively rapid catch-up, while other studies indicating that convergence may be slow or countries may be stuck in a bad equilibrium. ${ }^{3}$

One possible explanation for these apparent contradicting findings lies in the nature of the data that are employed. Using cross-country data, these studies leave unobserved a number of factors that may affect the relationship between conflict and economic performance. The speed of economic recovery may, for instance, depend on the type of damage caused by the war, for example, the destruction of physical capital may have different consequences compared to human capital destruction. The identity of the parties at war may also play a role, in particular whether the conflict was between states, often relying on professional armies, or within a state between fractions of society (some of them non-army forces). While these factors may play a role, they often remain unobserved in cross-country data. This makes estimates more sensitive to what part of the data is being analyzed and complicates accounting for endogeneity (since possible instruments may be correlated with the many factors that remain unobserved).

Using micro-level data is a promising way forward and generates new insights as (some of the) previously unobserved factors become observable. A small but growing literature therefore uses subnational-level data to study the social, political, and economic causes and consequences of violence. ${ }^{4} \mathrm{We}$ focus on the microeconomic analysis of the consequences of conflict, which is the subject of a small but emerging literature, discussed in the next section. Like these studies, this article concentrates on one country; but our approach differs from existing work in four ways. First, while existing empirical microeconomic work focuses on the effects of conflict 
between nations, this article looks at the effects within a country. Second, considering the dramatic events of 1994 in Rwanda, this study investigates the consequences of a destruction of human, rather than physical capital. Third, we consider a much shorter time horizon, assessing economic performance six years after the conflict. Finally, this article explicitly investigates the underlying post conflict process.

To study the effect of conflict on economic performance, we investigate whether rural households and communities that have experienced more conflict in 1994 have lower consumption six years after the end of the violence, relative to the other households and communities. We find that they do. This result remains after controlling for a wide range of community characteristics (including displacement) and after taking into account endogeneity, relying on the distance to the borders of Uganda and Nyanza, the former capital of the ancient Tutsi monarchy, as identifying instruments. Investigating the process of economic growth, we assess whether returns to factors of production depend on the experience of past conflict and find that returns to land are lower in conflict intense areas, which is consistent with a decrease in land pressure, and suggest an ongoing process of postwar catch-up. Finally, to investigate the role of human capital destruction, and exploiting the rare setting of simultaneous presence of genocide and civil war, we investigate whether different types of conflict have distinct effects and find that they do. Areas that experienced genocide have lower returns to land and higher returns to labor and education compared to other areas, while areas that experienced civil war have relatively lower returns to education. In a robustness check, these results are compared with those from a differencein-difference analysis relying on limited household income data from a prewar (1990) and postwar (2000) nationwide household survey. The results are very similar. By focusing on Rwanda, the study sheds light on the economic consequences of one of the largest and most recent genocides that happened in one of the most conflict-prone areas. It also provides rare micro evidence on the economic consequences of genocide and compares this with the effects of civil war, indicating that pathways to restoration depend on the type of violence experienced.

The remainder of this article is structured as follows. The second section discusses the conceptual framework and provides an overview of the relevant literature, while third section discusses the Rwandan context. After detailing our econometric strategy in the fourth section and discussing the data in fifth section, sixth section presents the results and the seventh section presents a series of robustness checks. The eighth section concludes.

\section{Conflict, Economic Performance, and Human Capital}

Conflict has many consequences, including social, political, and economic ones. There is a rich literature investigating the effects of conflict and political violence on social and political factors. ${ }^{5}$ This article focuses on the economic consequences of conflict. ${ }^{6}$ Conceptually, our benchmark is a growth model that includes human capital and is of the general form $Y=A K^{\alpha} L^{\beta} H^{\gamma}$. ${ }^{7}$ This model predicts that 
economies converge to their own steady state, with the speed of convergence depending on the distance from the steady state, assuming decreasing returns to individual production factors. A reduction in physical or human capital will result in a more rapid accumulation of physical or human capital after the conflict, and the economy will converge to its steady state, assuming that other parameters in the model do not change. Barro and Sala-i-Martin (2004) predict that the speed of recovery depends on the type of capital that is destroyed, with a slower recovery if human capital, rather than physical capital, is destroyed, because it has a higher adjustment cost. ${ }^{8}$ Endogenous growth models, as well as poverty trap models, predict that conflict has a direct effect on an economy's steady state, and as a result otherwise similar economies do not converge (Azariadis and Drazen 1990; Rodrik 1999; Collier 1999).

Existing empirical evidence, mostly relying on cross-country data, does not allow rejecting either of these views. Organski and Kugler (1977), among the first to present evidence on catch-up, find that, while economies suffered heavy short-term losses from the two world wars, these effects dissipated after 15-20 years, when the economy had returned to prewar growth trends. Cerra and Saxena (2008) also find that, while output falls steeply immediately after the conflict ( 6 percent on average), the economy recovers relatively soon afterward, with, in their case, half of the fall made up within a few years. Murdoch and Sandler (2004), on the other hand, find that civil war reduces a country's growth by 85 percent in the first five years, and while there is recovery, growth is still reduced by 31 percent after thirty-five years. Rodrik (1999) argues that growth rates have lacked persistence in many countries since the 1970s because of domestic conflict. Collier (1999) lays out how civil war reduces the desired stock of factors of production, and how the duration of civil war affects postwar performance (with longer conflict durations leading to higher postwar growth). ${ }^{9}$

However, because these articles rely on cross-country data, accounting for causality remains a challenge, and the results may be fragile, as argued in the introduction. ${ }^{10}$ Cross-country analysis on the economic consequences of violence also rarely takes into account the nature of conflict, considering the joint effects of war between states, which is associated with large-scale destruction of physical capital, and civil conflict, which tends to be more detrimental for human capital, institutions, and social order (see Collier 1999). ${ }^{11}$ Finally, the use of cross-country data implies an implicit focus on middle- and high-income countries, since data for poor countries that remain in conflict is typically absent, thus introducing a selection bias. ${ }^{12}$

To address these shortcomings, recent work makes use of micro-level data, comparing outcomes between neighboring areas with different exposure to conflict. Much has been learned about the political dimensions of conflict from this type of work. ${ }^{13}$ An emerging literature applies a similar approach to analyze the economic consequences of conflict. Three articles stand out for our purpose. Davis and Weinstein (2002) show that Japanese cities that were bombed had completely recovered in size twenty years after the US bombing in World War II. In a similar vein, 
Brakman, Garretsen, and Schramm (2004) find that bombing of Germany had a significant but temporary impact on postwar city growth in West Germany but a sustained impact in East Germany. Miguel and Roland (2011), finally, studying the effect of the destruction of physical capital by the bombing in Vietnam, find that the economy in hit areas had recovered thirty years after the conflict in terms of consumption, infrastructure, poverty, literacy, and population density. ${ }^{14}$ All three studies look at the effects of physical capital destruction, several decades after an international conflict. This article differs in four ways: it studies the consequences of the destruction of human capital caused by civil conflict, much shorter after the conflict, and provides insight into the underlying mechanisms of postwar growth. ${ }^{15}$

Although there is, by our knowledge, little direct evidence on the impact of human capital destruction on economic growth, two existing studies indicate that the effects of a sudden drop in human capital can be profound. Historical research suggests that the black death in the mid-14th century led to a change in the land labor ratio and resulted in a rise in real wages, leading to the start of the "Golden Age of the English Labourer" (Farmer 1991). ${ }^{16}$ A second example is provided by Young (2005). Investigating the effect of high infection rates of human immunodeficiency virus (HIV) on future living standards in South Africa, the author shows that the negative effect on human capital accumulation (especially for orphans) is compensated by a positive effect of slower population growth, which is caused by both a lower sexual activity and an increase in the value of woman's time due to the increased scarcity of labor associated with high mortality.

There is ample evidence that conflict can have strong impacts on human capital. With respect to health, Alderman, Hoddinot, and Kinsey (2006), analyzing data for Zimbabwe, find that greater exposure to civil war has a negative effect on child height. Bundervoet, Verwimp, and Akresh (2009), focusing on Burundi, find that an additional month of war decreased children's height for age $z$ scores by .05 standard errors compared to nonaffected children; and Arcand and Wouabe (2009) find that conflict intensity worsened child health during and after the conflict in Angola. ${ }^{17}$ There is also micro evidence for the effects of conflict on education. Akresh and de Walque (2008) show that the armed conflict in Rwanda had a negative effect on schooling outcomes, with exposed children completing half a year less. De Walque (2004) discusses how civil conflict in Cambodia had a lasting impact on educational attainment, mostly because of the collapse of the education system, and Shemyakina (2011) presents evidence of the negative impact of conflict on schooling in the case of Tajikistan. Chamarbagwala and Morán (2011) find a strong negative effect of the civil war in Guatemala on the education of Mayan men and women in rural areas, the most disadvantaged groups. In contrast, Arcand and Wouabe (2009), find that conflict increased school enrollment in Angola. Blattman and Annan (2010) find that child soldiering has persistent educational and labor impacts later in life, with schooling close to one year lower, employment chances halved, and earnings one-third lower for ex-child soldiers. These results, and others summarized in an earlier literature review by Justino (2007), indicate that conflict 
can have profound negative effects on human capital, thereby sustaining poverty and slowing down economic recovery.

\section{The Context of Rwanda}

This study focuses on the violence that took place in Rwanda in 1994. In April of that year, when the plane carrying President Habyarimana was shot down, genocide broke out, and the civil war between the Rwandan Patriotic Front (RPF) and the Rwanda government, which had been halted the year before, restarted and intensified. ${ }^{18}$ By the end of June 1994, the RPF had taken control of the country and had put an end to the ethnic cleansing of Tutsis. Relative peace was established, although militias from the old regime (FAR and Interahamwe) continued with insurgencies in the northwest for some time.

The conflict in Rwanda is of interest for several reasons. As one of the largest and most recent genocides, and taking place in one of the most conflict prone areas, the Rwanda conflict has acquired a high profile, because of both the number of victims and the special status of genocide. ${ }^{19}$ The understanding of genocide and its consequences is limited, and micro-level analysis of genocide remains extremely rare. ${ }^{20}$ Perhaps less well known is that the outbreak of the genocide reactivated a civil war, leading to the simultaneous presence of two types of conflict and providing the unusual occasion to study the distinct effects of different types of violence at the same time. ${ }^{21}$ Recent work has shown an increased interest in the study of different types of violence, distinguishing for instance by the scale of conflict (typically measured by the level of battle deaths), whether religious and ethnic identities play a role, the origin and parties at war, or the ideology of the warring factions. ${ }^{22}$ This article considers both civil war and genocide and investigates their distinct economic consequences. This is also of special interest to researchers of postwar recovery and policy makers. If different types of conflict have variable economic consequences, pathways to recovery are distinct, and specific policies that depend on the type of violence may be needed to promote post conflict recovery. While the specific context of Rwanda may appear to limit what we can learn for other settings, the focus on economic processes, and using empirical analysis grounded in economic theory, allows for a comparison across contexts leading to fresh insights. ${ }^{23}$

Rwanda thus experienced distinct forms of violence, which were concentrated in different geographical areas and had different consequences. Although civil war took place in most of the northern and eastern provinces, as well as in the center, the genocide was concentrated in the south. While the genocide had a high direct death toll, up to 800,000 , mostly targeting the active male Tutsi population, and in particular the educated ones, ${ }^{24}$ the civil war was characterized by indirect deaths caused by a variety of factors, including limited access to food and health care, and took its largest toll among the weakest in the population (Verpoorten 2012). Although there is to our knowledge no full assessment of the physical capital destroyed by civil war 
and genocide respectively, the former, with its aim to gain ground and sabotage government, is generally associated with more physical capital destruction. Two illustrations are the damage to the Ntaruka power station (by RPF) and Cyangugu tea factory (by FAR), as mentioned by Justino and Verwimp (2006).

There is only a small body of evidence documenting the economic setback caused by the conflict in Rwanda. Lopez and Wodon (2005) using aggregate data over time argue that, without the occurrence of conflict, gross domestic product (GDP) per capita in 2000 would have been 25 percent to 30 percent higher in Rwanda. Verpoorten and Berlage (2007) make use of a small panel data set including about 200 households in two provinces to study income mobility and find that genocide-related household-level shocks between 1990 and 2002 had very little effect on households' income mobility. Using the same data, Verpoorten (2009) studies the use of cattle as a buffer against war-related shocks, reporting that cattle stock had fallen by half during 1994, but bounced back to about 74 percent of its prewar level by 2002. Justino and Verwimp (2006) provide descriptive evidence for convergence at the province level $(N=10)$ and hypothesize that this is related to a number of factors including changes in labor-capital ratios, the location of battles, waves of migration, and local resurgences. ${ }^{25}$ The present study differs from these related studies by performing a rigorous regression analysis using a nationally representative sample and detailed commune-level conflict intensity measures that were previously not available.

A second group of studies, mentioned earlier, have focused on the consequences of conflict for human capital in Rwanda. Akresh, Verwimp, and Bundervoet (2011) show how the 1991-1992 conflict resulted in reduced height-for-age $z$ scores for children living in conflict zones. McKay and Loveridge (2005) show how national nutrition levels - an important input to health - had recovered completely by 2000 to their 1992 levels. Looking at education levels, Akresh and de Walque (2008) find a substantial and significant fall (18 percent) in education attainment for children exposed to armed conflict. Only the latter study takes endogeneity of conflict into account.

While the first set of studies, looking at the consequences of conflict for economic performance, remains at the aggregate level, uses small nonrepresentative data sets, or considers measures other than (the preferred) household consumption, the studies looking at education and health assess differences within the country but do not make the explicit link to economic performance. This article brings these two strands closer together.

This study focuses on rural areas, or the agricultural sector, which harbored over 90 percent of the population at the peak of the conflict, and plays a dominant role in Rwanda's economy. This allows us to abstract from the strong differences in the nature of the production process between the rural and urban sector (see our production function approach below). Conceptually the context of rural Rwanda provides an additional dimension of interest. Having one of the highest population densities in sub-Saharan Africa, and harboring surplus labor, it provides a setting that allows studying what happens if population density is reduced substantially in a short period. ${ }^{26}$ 


\section{Econometric Strategy}

To investigate the effect of conflict on economic performance, and assess the role of human capital destruction, this article tests three hypotheses. It first tests whether households and communities that have experienced conflict in 1994 have lower consumption six years after the conflict ended, than to the other households and communities. Second, it examines the process of postwar economic growth, by comparing the returns to factors of production between heavily affected areas and less affected areas. In a robustness check we also investigate whether the results remain when taking migration into account. Finally, we test whether areas that have experienced distinct types of conflict, namely genocide and civil war, which are associated with human and physical capital destruction, respectively, have different levels of economic performance and yield different returns to factors of production.

\section{Conflict and Economic Performance}

To study the effect of conflict on economic performance the following equation is estimated:

$$
y_{i}=\beta_{0}+\beta_{1} C_{i}+A X_{i}+B P_{i}+\varepsilon_{1 i} \text { with } H_{0}: \beta_{1}=0,
$$

where $y$ is the log of household consumption, $C$ is a conflict index, as discussed in detail in the fifth section, $X$ is the control variable (also discussed in the fifth section), and $P$ province fixed effects.

Since conflict intensity is related to economic factors, including land scarcity and income inequality among farmers in the case of genocide, as documented among others by André and Platteau (1998), equation (1) may suffer from endogeneity. To address this, the following instrumental variable (IV) estimation is carried out:

$$
\begin{gathered}
y_{i}=\beta_{0}^{\prime}+\beta_{1}^{\prime} \hat{C}_{i}+A^{\prime} X_{i}+B^{\prime} P_{i}+\varepsilon_{1 i}^{\prime} \text {, with } H_{0}: \beta_{l}^{\prime}=0, \\
C_{i}=\gamma_{0}+\Gamma_{1} Z_{i}+\Gamma_{2} X_{i}+\Gamma_{3} P_{i}+\varepsilon_{2 i}^{\prime} .
\end{gathered}
$$

Two instrumental variables $\left(Z_{i}\right)$ are used to proxy exogenous geographical variation in conflict intensity namely the distance to Uganda $\left(\mathrm{DU}_{i}\right)$ and Nyanza $\left(\mathrm{DN}_{i}\right)$. Because the RPF infiltrated from Uganda and gradually moved toward Kigali, engaging in heavy battles with the Rwandan army before eventually taking over the capital, ${ }^{27}$ distance to Uganda is appropriate as an identifying instrument. The exogenous character of the border stems from colonial history, as the border between Uganda and Rwanda was fixed in 1910 at an Anglo-German-Belgian Convention in Brussels, which provided that the boundary between British and German territories should follow the parallel of one degree south latitude across Lake Victoria and should continue westward to its intersection with the thirtieth meridian of longitude east of Greenwich (Bureau of Intelligence and Research 1965). ${ }^{28}$ 
Distance to Nyanza, the original capital of the Tutsi monarchy that ruled most of Rwanda's territory between the fifteenth and nineteenth century, serves as the second identifying instrument for conflict intensity. Its economic and political importance faded during colonization and was over by independence in $1962 .^{29}$ Today nothing is left of Nyanza's past glory. Its population density and economic development is indistinguishable from surrounding areas, but the proportion of Tutsi in the communities close to Nyanza was, for historical reasons, still higher prior to the genocide. However, note that even in the communities close to Nyanza, Tutsi remained a minority group and did not outnumber Hutu.

The distance to the border with Uganda and the distance to Nyanza qualify as appropriate instruments, provided that they do not have a direct effect on economic performance, other than through the conflict. Therefore, in the estimated model, these instruments are used conditional on control variables like population density and distances to the road and the capital (although results remain when dropping these controls). As described in more detail in the sixth and seventh sections, the usual overidentification tests as well as a Conley test support the validity of these instruments.

\section{Investigating the Process of Economic Growth: Conflict and Factors of Production}

Theory argues that if conflict affects economic performance, it must be because it affects the factors of production, or their prices, or the technology or institutions augmenting these factors. ${ }^{30}$ To study the role of production factors in the presence of conflict, we estimate a standard production function that includes the conflict variable, while taking its endogeneity into account:

$$
\begin{aligned}
& y_{i}=\alpha_{0}+\alpha_{1} k_{i}+\alpha_{2} l_{i}^{u}+\alpha_{3} l_{i}^{s}+\alpha_{4} \hat{C}_{i}+A^{\prime \prime} X_{i}+B^{\prime \prime} P_{i}+\varepsilon_{1 i}^{\prime \prime}, \\
& C_{i}=\gamma_{0}^{\prime}+\gamma_{1}^{\prime} D U_{i}+\gamma_{2}^{\prime} D N_{i}+\gamma_{3}^{\prime} k_{i}+\gamma_{4}^{\prime} l_{i}^{u}+\gamma_{5}^{\prime} l_{i}^{s}+\Gamma_{6} X_{i}+\Gamma_{7} P_{i}+\varepsilon_{2 i}^{\prime \prime},
\end{aligned}
$$

where $k$ reflects land owned, $l^{u}$ stands for unskilled, and $l^{s}$ for skilled labor. The coefficient $\alpha_{4}$ reflects by how much output is lower in areas that have experienced more intensive conflict, after controlling for factors of production, for instance, because of structural reasons, like technology or institutions, or due to market frictions. We test $H_{0}: \alpha_{4}=0$, which would be rejected in a poverty trap model as well as in a neoclassical model if the economy converges to a new (lower) steady state.

To assess whether returns to production factors are different in areas that have experienced conflict, the conflict variable is interacted with each of the production factors. To account for the possible endogeneity of conflict, we instrument for conflict as well as for its interactions with the three production factors. In order to do so, we follow the three-step procedure described in Wooldridge $(2000,236)$. In the first step, we predict conflict intensity by regressing $C_{i}$ on the set of included instruments 
as well as the set of excluded instruments $\left(\mathrm{DU}_{i}\right.$ and $\left.\mathrm{DN}_{i}\right)$. Next, predicted conflict intensity is interacted with the production factors, yielding a set of three interaction terms that are then used as additional instruments in a conventional two-stage least squares procedure. Formally, we estimate the following set of equations:

$$
\begin{aligned}
y_{i}= & \alpha_{0}^{\prime}+\alpha_{1}^{\prime} k_{i}+\alpha_{2}^{\prime} l_{i}^{u}+\alpha_{3}^{\prime} l_{i}^{s}+\alpha_{4}^{\prime} \widehat{\hat{C}}+\alpha_{5}^{\prime}\left(k_{i} \widehat{\times C_{i}}\right)+\alpha_{6}^{\prime}\left(l_{i}^{u} \widehat{\times C_{i}}\right)+\alpha_{7}^{\prime}\left(l_{i}^{s} \widehat{\times C_{i}}\right) \\
& +A^{\prime \prime \prime} X_{i}+B^{\prime \prime \prime} P_{i}+\varepsilon_{1 i}^{\prime \prime \prime}, \\
C_{i}= & \gamma_{0}^{\prime \prime}+\gamma_{1}^{\prime \prime} D U_{i}+\gamma_{2}^{\prime \prime} D N_{i}+\gamma_{3}^{\prime \prime} k_{i}+\gamma_{4}^{\prime \prime} l_{i}^{u}+\gamma_{5}^{\prime \prime} l_{i}^{s}+\gamma_{6}^{\prime \prime}\left(k_{i} \times \hat{C}_{i}\right)+\gamma_{7}^{\prime \prime}\left(l_{i}^{u} \times \hat{C}_{i}\right) \\
& +\gamma_{8}^{\prime \prime}\left(l_{i}^{s} \times \hat{C}_{i}\right)+\Gamma_{9} X_{i}+\Gamma_{10} P_{i}+\varepsilon_{2 i}^{\prime \prime}, \\
\left(k \times C_{i}\right)= & \gamma_{0}^{\prime \prime \prime}+\gamma_{1}^{\prime \prime \prime} D U_{i}+\gamma_{2}^{\prime \prime \prime} D N_{i}+\gamma_{3}^{\prime \prime \prime} k_{i}+\gamma_{4}^{\prime \prime \prime} l_{i}^{u}+\gamma_{5}^{\prime \prime \prime} l_{i}^{s}+\gamma_{6}^{\prime \prime \prime}\left(k_{i} \times \hat{C}_{i}\right) \\
& +\gamma_{7}^{\prime \prime \prime}\left(l_{i}^{u} \times \hat{C}_{i}\right)+\gamma_{8}^{\prime \prime \prime}\left(l_{i}^{s} \times \hat{C}_{i}\right)+\Gamma_{9}^{\prime} X_{i}+\Gamma_{10}^{\prime} P_{i}+\varepsilon_{2 i}^{\prime \prime \prime}, \\
\left(l_{i}^{u} \times C_{i}\right)= & \gamma_{0}^{\prime \prime \prime \prime}+\gamma_{1}^{\prime \prime \prime \prime} D U_{i}+\gamma_{2}^{\prime \prime \prime \prime} D N_{i}+\gamma_{3}^{\prime \prime \prime \prime} k_{i}+\gamma_{4}^{\prime \prime \prime \prime} l_{i}^{u}+\gamma_{5}^{\prime \prime \prime \prime} l_{i}^{s}+\gamma_{6}^{\prime \prime \prime \prime \prime}\left(k_{i} \times \hat{C}_{i}\right) \\
& +\gamma_{7}^{\prime \prime \prime \prime}\left(l_{i}^{u} \times \hat{C}_{i}\right)+\gamma_{8}^{\prime \prime \prime \prime}\left(l_{i}^{s} \times \hat{C}_{i}\right)+\Gamma_{9}^{\prime \prime} X_{i}+\Gamma_{10}^{\prime \prime} P_{i}+\varepsilon_{2 i}^{\prime \prime \prime \prime}, \\
\left(l_{i}^{s} \times C_{i}\right)= & \gamma_{0}^{\prime \prime \prime \prime \prime}+\gamma_{1}^{\prime \prime \prime \prime \prime} D U_{i}+\gamma_{2}^{\prime \prime \prime \prime \prime} D N_{i}+\gamma_{3}^{\prime \prime \prime \prime \prime} k_{i}+\gamma_{4}^{\prime \prime \prime \prime \prime} l_{i}^{u}+\gamma_{5}^{\prime \prime \prime \prime \prime} l_{i}^{s}+\gamma_{6}^{\prime \prime \prime \prime \prime}\left(k_{i} \times \hat{C}_{i}\right) \\
& +\gamma_{7}^{\prime \prime \prime \prime \prime}\left(l_{i}^{u} \times \hat{C}_{i}\right)+\gamma_{8}^{\prime \prime \prime \prime \prime}\left(l_{i}^{s} \times \hat{C}_{i}\right)+\Gamma_{9}^{\prime \prime \prime \prime} X_{i}+\Gamma_{10}^{\prime \prime \prime} P_{i}+\varepsilon_{2 i}^{\prime \prime \prime \prime} .
\end{aligned}
$$

where $\hat{C}_{i}$ is obtained from equation (5). If there is rapid catch-up, returns to production factors are expected to be the same across areas with low and high violence intensity, or $H_{0}: \alpha_{5}^{\prime}=\alpha_{6}^{\prime}=\alpha_{7}^{\prime}=0$.

Ceteris paribus one would expect the mass killings that characterized the conflict in Rwanda to increase returns to labor. However, if surplus labor was substantial, these returns may remain low, even after the mass killing. Conversely, while returns to land are likely to be high in Rwanda's setting of extreme land scarcity, they may be lower in conflict intensive areas. Turning to skilled labor, given the general low levels of education, one expects returns to skilled labor to be positive and large, and-because the genocide targeted the more educated, as shown by de Walque and Verwimp (2010) — one expects, ceteris paribus, these returns to be higher in areas that experienced genocide more intensively.

\section{Taking Migration into Account}

Migration, including both war-induced displacement and resettlement, may affect economic performance and catch-up. Therefore, we investigate whether the results are robust to controlling for migration. ${ }^{31}$ Since the process of migration may be simultaneous to that of economic development, we account for its endogeneity. Because by far most migration in postwar Rwanda was related to war-induced displacement and resettlement, we use the same instruments as before. The estimation 
is similar as above, with an additional first-stage regression for migration (of which the predicted variable is then added to the second-stage regression). If migration has an effect on its own, one expects its coefficient to be significantly different from zero. More importantly for our purpose, we assess whether the earlier results on our coefficients of interest remain.

\section{Does the Type of Conflict Play a Role?}

Considering the two types of conflict that took place in Rwanda in 1994, namely genocide and civil war, which are associated with human and physical capital destruction, respectively, we reestimate the above equations using these conflict specific indices (see fifth section). Because the genocide targeted individuals, and specifically able and active men, we expect the difference in returns to labor between areas that were affected by the genocide and those that were not, to be larger than the difference between areas that experienced civil war and those that did not. Given that the genocide also targeted the relatively educated, we also expect differences in returns to skilled labor.

\section{Data and Measurement}

We combine three types of data: the 1999-2000 national household survey (Enquête Intégrale sur les Conditions de Vie des Ménages [EICV]/Integrated Household Living Conditions Survey [IHLCS] ${ }^{32}$ ), conflict data derived from two consecutive population censuses and the records of the gacaca (a transitional justice system for genocide suspects), and geographical data to define the instruments. The compiled data set has variables at the household, sector, and commune level. ${ }^{33}$ Consumption and household production factors are at the household level, while the conflict index and instrumental variables are at the commune level, and most control variables are at the sector level. To show the robustness of the results, we run the regressions both at the household and sector level. The standard errors in the household-level regressions are adjusted for clustering at the sector level. The first-stage regressions are always at the commune level. We discuss the key variables in turn.

Economic performance, which is measured at the household level, is proxied by household consumption and obtained from the IHLCS 1999-2000. ${ }^{34}$ Table 1 reports the descriptive statistics, showing that average annual (rural) household consumption is 271,776 Rwandan franc (RWF) or 693 USD (purchasing power parity [PPP]) or 158 USD (PPP) per capita. ${ }^{35}$ The average amount of land owned is .37 ha, while the average number of active household members (those aged between fifteen and sixty-five), which is our proxy for unskilled labor, is 2.09. Mean year of schooling of the household head, our proxy for skilled labor, is $2.68 .^{36}$

The conflict measures are from Verpoorten (2011) who develops three indices reflecting the intensity of the conflict in general, genocide, and civil war, respectively. They are calculated at the commune level from the 2002 population census 


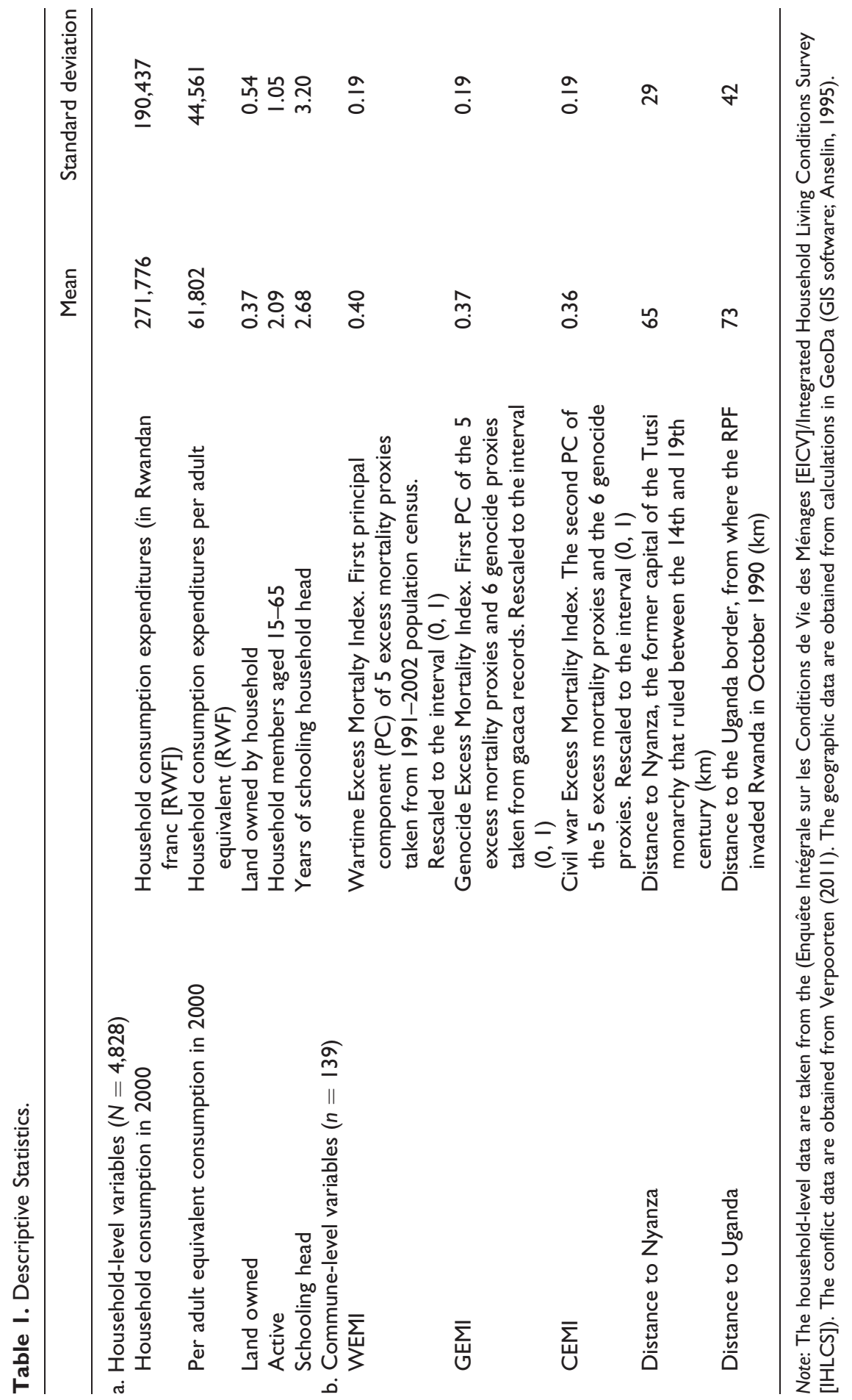


data $(N=8.1$ million), a 10 percent sample of the 1991 population census data ( $N=742,918$ individuals), and the records of the gacaca, the transitional justice system for judging genocide suspects. Here we limit ourselves to a brief description of the measures; details can be found in the online appendix.

General conflict intensity is measured by the Wartime Excess Mortality Index (WEMI), which measures commune-level excess mortality in the period 1991-2002 and is the weighted sum of the first differences of five excess mortality proxies derived from the 1991 and 2002 population census, in particular, the mortality of sons, the mortality of daughters, widowhood, orphanhood, and disability due to war or genocide. ${ }^{37}$ In line with previous work on the construction of conflict indices, the weights equal the vector of (positive) loadings of the first principal component (PC) (e.g., Hibbs 1973; Venieris and Gupta 1986; González and Lopez 2007). These loadings and the summary statistics for the five 1991-2002 excess mortality proxies are listed in Table A1 in the online appendix.

To proxy for the intensity of genocide, the previously mentioned set of five general excess mortality measures is augmented with an extra six genocide proxies, namely the number of genocide suspects (using three different categories) and the number of genocide victims who survived but lost close relatives in the genocide (widowed, orphaned, and disabled genocide victims); all taken proportional to the population. When subjected to principal component analysis, the loadings on the first PC are positive across the eleven variables and highest on the genocide proxies, indicating that the first component can be interpreted as reflecting genocide-specific excess mortality. The loadings on the second PC are positive on the general excess mortality proxies, but negative on the genocide proxies, allowing us to interpret PC 2 as reflecting the intensity of civil war rather than genocide. ${ }^{38}$ For ease of interpretation, each of the indices are rescaled to fall in the $(0,1)$ interval. The standard deviation of the indices, reported in Table 1, indicates that there is substantial variation in exposure to violence across communes. ${ }^{39}$ To visualize the geographical spread, Figure 1 presents a map for each of the three indices, with a darker shade reflecting a higher mortality index. These maps confirm that Genocide Excess Mortality Index (GEMI) is concentrated in the South, while Civil war Excess Mortality Index (CEMI) is concentrated in the center, east, and northwest, which is consistent with the findings from event data analysis on the different forms of violence (Des Forges 1999; Justino and Verwimp 2006).

To reduce sample heterogeneity, the regression controls for a number of preconflict commune and sector characteristics, including sector-level precipitation and altitude to control for differences in climate and geography (which determine agricultural conditions, like soil type). ${ }^{40}$ The model also includes 1991 sectorlevel population density and 1978-1991 commune-level population growth, which both proxy for differences in land productivity. ${ }^{41}$ It further includes the 1991 sector-level distance to a main road and distance to Kigali, which proxy for market integration and proximity to the economic center, and because civil war tended to be more intense in sectors closer to the main road and closer to Kigali. However, the 


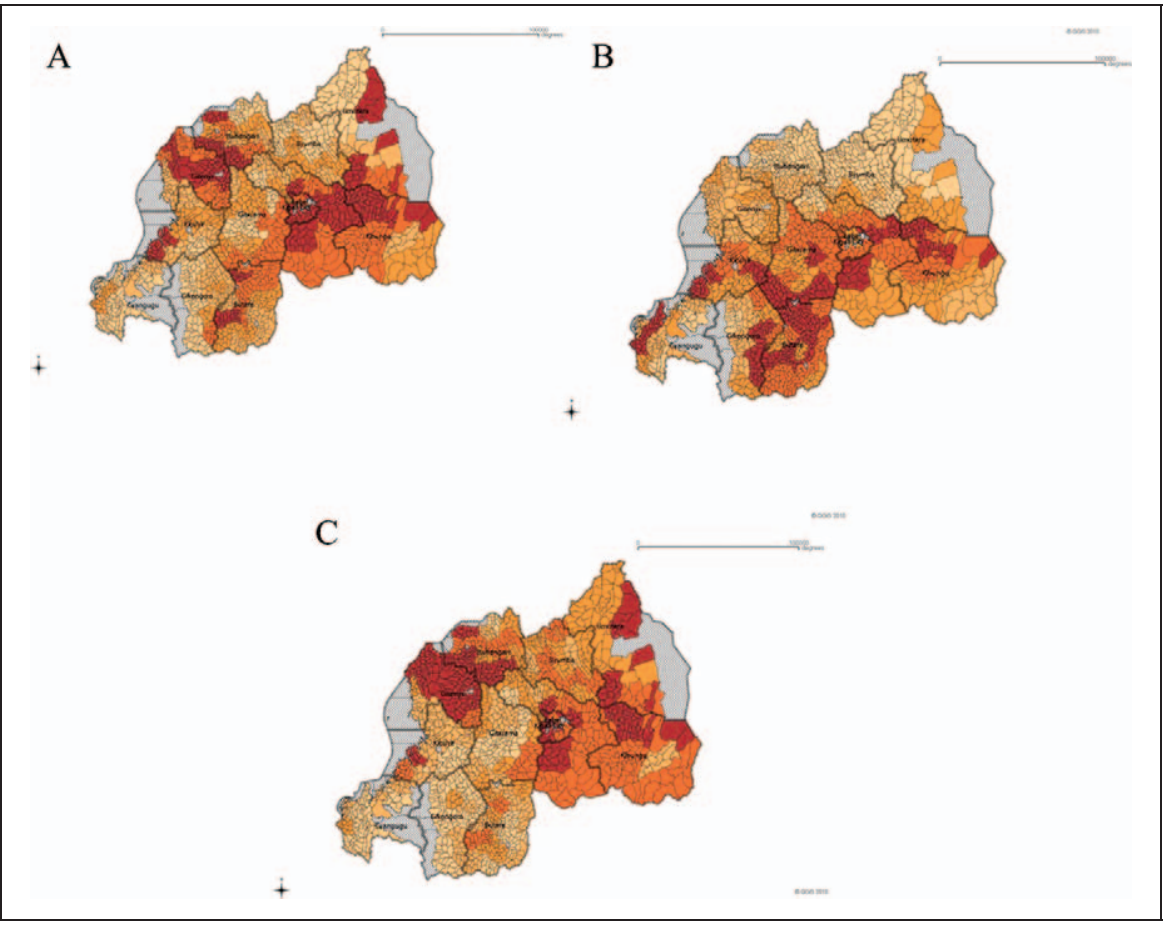

Figure I. Geographical distribution of the conflict indices expressed in (darkest reflects top quintile). A, War Excess Mortality Index (WEMI). B, Genocide Excess Mortality Index (GEMI). C, Civil War Excess Mortality Index (CEMI).

control variables are not crucial as the results remain similar when excluding these variables, for which summary statistics are listed in the online appendix Table A2.

\section{Results}

\section{Do War-affected Areas Perform Worse Six years after the Conflict Ended?}

Table 2 reports the results from estimating equation (1) first at the sector level (columns 1-3) and then at the household level (columns 4-9). In each case, ordinary least square (OLS) estimates are reported first, followed by the IV and first-stage estimates. The results are very robust. According to OLS, sectors that experienced maximum violence in 1994 (having a value of 1 for the conflict index) had 36 percent lower consumption levels in 2000 than sectors that experienced no conflict in 1994 (0 value of the index). The IV approach yields a substantially larger negative estimate and finds that consumption in areas that experienced maximum conflict is 88 percent lower than in zero conflict areas. The substantially higher IV estimates 


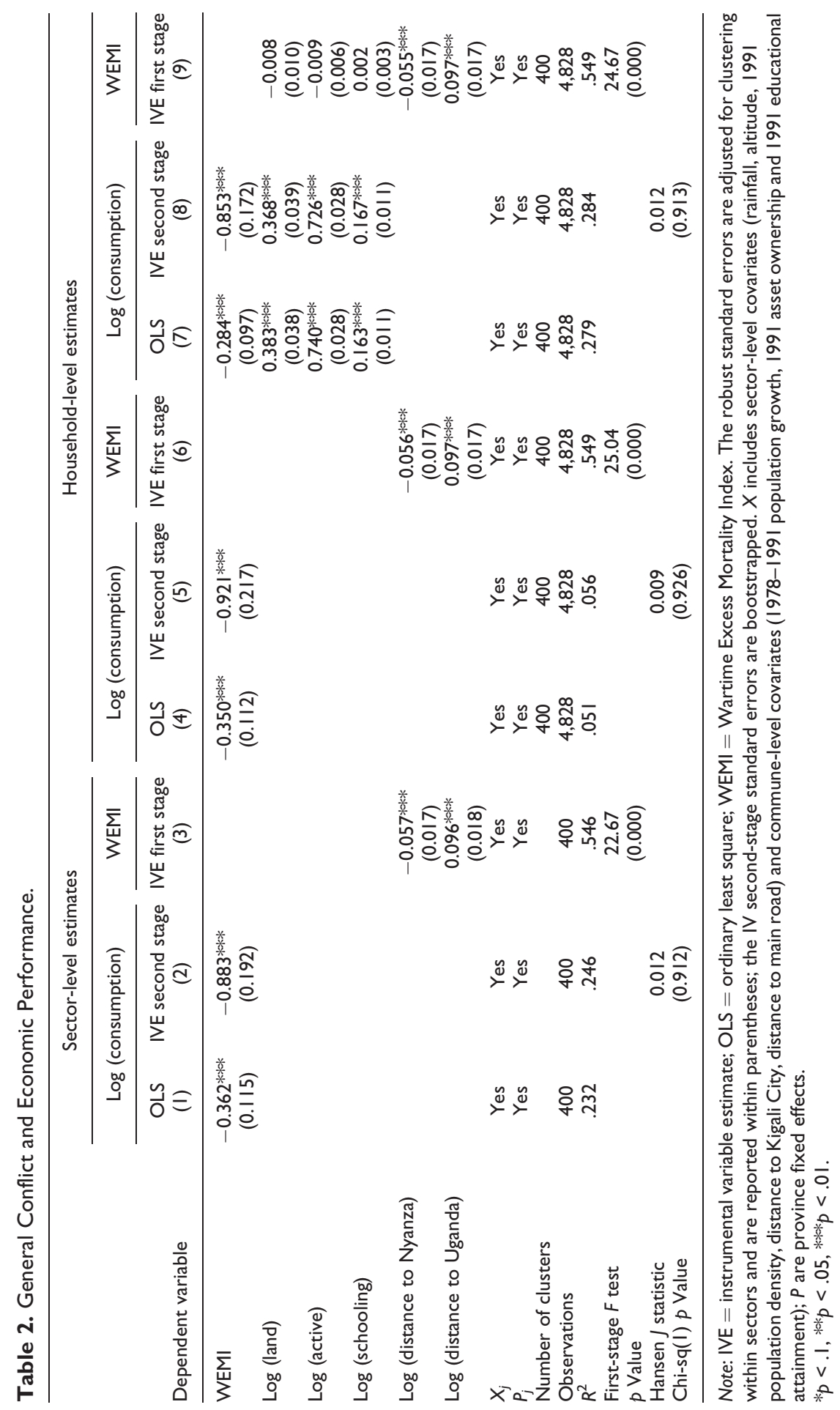


indicate that richer areas suffered more intensive violence, biasing the OLS estimate upward. Applying equation 1 to the household data yields very similar results, namely -.35 for the OLS estimate and -.92 for the IV estimate, as reported in columns 4 to 5 in Table 2 .

The reported coefficients reflect what happens when moving from minimum to maximum conflict intensity and therefore tend to be large. When expressing the effect in standard deviations, the respective coefficients are considerably smaller, namely -.07 (rather than .36 ) for OLS and -.17 (rather than -.88 ) for IV at the sector level and .07 (rather than .35) and .19 (rather than .92) for the OLS and IV estimates at the household level.

The first-stage regression reported in Table 2 column 3 demonstrates the importance of both instruments, which show up highly significant and have the expected signs. Distance to Nyanza has a negative sign, reflecting high conflict and genocide intensity near Nyanza. Distance to Uganda has a positive sign, indicating high conflict intensity further away from the border with Uganda, reflecting the 1994 civil war in the center and the east, with the battle intensifying as the RPF proceeded. ${ }^{42}$ The $F$ statistics are all well above 10, confirming the instruments' strength. A Sargan-Hansen test of overidentification also performs well as the joint null hypothesis that the instruments are uncorrelated with the error term cannot be rejected, supporting the validity of our instruments. Since the Wooldridge procedure to instrument for interaction terms yields biased standard errors, we report bootstrapped standard errors for the second stage. ${ }^{43}$

To estimate equations (4) and (5), the model is then extended to include land owned as well as skilled and unskilled labor in the household. The results, reported in columns 7 to 9 in Table 2, confirm earlier results and show that conflict has a large significant negative effect, both in OLS and in IV estimation, with the latter again larger in magnitude. This indicates that even after controlling for household endowments, those living in areas that experienced more intensive violence perform worse six years after the conflict ended. The estimates also confirm that the returns to land, unskilled and skilled labor are all positive and significant.

Although the approach followed in this article is not well suited to make a country wide assessment, it is still interesting to carry out a simulation to approximate the nationwide effect of conflict. Assuming everything else remains the same, which may be a conservative assumption, we obtain an idea of the nationwide effect by multiplying the point estimate with the conflict index, taking into account the entire distribution of conflict intensity. Using the IV (OLS) estimate, we find that consumption in rural areas would have been 35 percent (14 percent) higher if there would not have been excess mortality. This estimate closely matches the findings of Lopez and Wodon (2005) who extrapolate a national trend in GDP (including urban areas) and conclude that GDP/capita would have been 25 percent to 30 percent higher in Rwanda if there would not have been conflict. 


\section{Are Returns to Factors of Production Different for Areas that Have Experienced Conflict?}

One possible reason why conflict areas have lower consumption is that recovery takes time, and six years is too short. If this is the case, we should see mechanisms for catch-up at play. The results of estimating equation (6), presented in Table 3, indicate that while the return to land is positive in general, it is basically zero in areas with maximum past conflict. This is consistent with land becoming less scarce due to excess mortality. Alternative explanations, like a lack of complementary inputs due to market disruption, are also possible. The returns to unskilled labor are slightly higher in areas with high intensity of violence but not significantly so. This seems at least partially the consequence of unobserved heterogeneity in the form of violence (as we demonstrate in the section on Does the Type of Conflict Matter?). Returns to skilled labor are slightly lower in conflict areas (but not significantly), contrary to our expectations (since the genocide targeted the most educated). This may suggest that activities where returns to education are highest, like off farm work, may still be largely absent in past conflict areas, for instance because of a lack of infrastructure, or that the educated have been replaced by equally educated immigrants.

\section{Controlling for Migration}

So far migration has not been taken into account. In the aftermath of genocide, a substantial number of people have been displaced both internally and externally. ${ }^{44}$ However, by 2000 more than 97 percent of the refugees who moved abroad had returned to Rwanda (UNHCR 2000). These returnees, as well as the internally displaced, did not necessarily resettle in their communities of origin. The relevant dimension of migration to focus on in this analysis is therefore resettlement in a Rwandan community different from one's pregenocide residence. Results from the 2002 population census show that this is limited in scale, with 8.3 percent of the population residing in a different community from where they resided before the start of the conflict in 1991 (Government of Rwanda 2002). Nevertheless, this may influence our estimation results as migration may affect labor supply and economic performance.

To check the robustness of the results, we add the proportion of immigrants in a sector (calculated from the entire 2002 population census) to our model, as set out in the section on Taking Migration into Account, and take endogeneity of immigration into account using the same identifying instruments. Table A3 in the online appendix reports the results of the household-level estimation. In both OLS (column 1) and IV (column 2), the estimated coefficient of conflict is very close to the original estimates reported in Table 2 (columns 4 and 5). The results in columns 3-6 confirm that the coefficients of the household production factors and of the interaction terms 


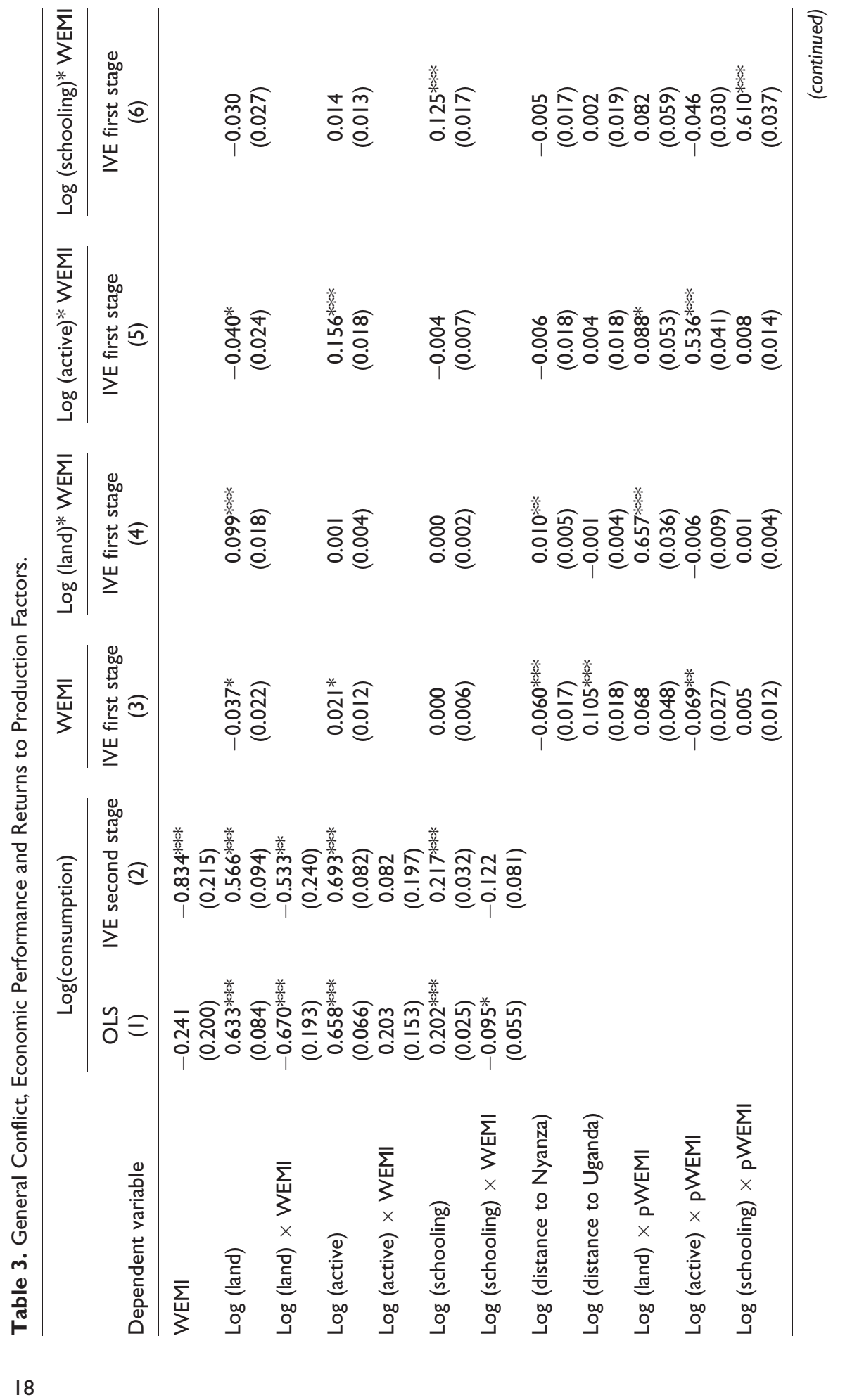




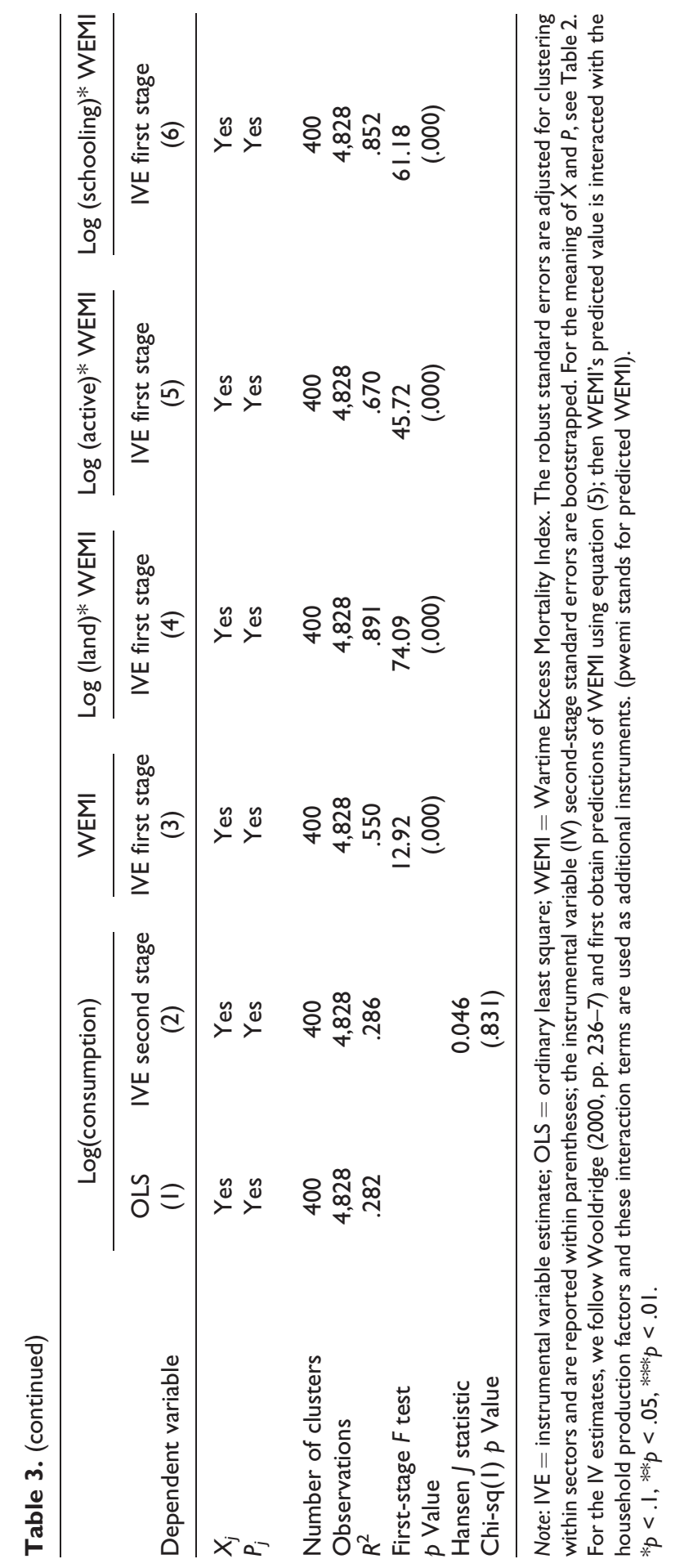


between conflict measures and household production factors also remain virtually unchanged after controlling for immigration.

In the first-stage regressions for immigration (not reported), distance to Nyanza has a high predictive power, while distance to Uganda does not show up significantly. This is consistent with immigration being concentrated in communities that are affected by the genocide.

\section{Does the Type of Conflict Matter?}

Table 4 reports OLS and IV estimates for the different types of conflict, replacing the general conflict index (WEMI) with the genocide (GEMI) and civil war (CEMI) indices, respectively. ${ }^{45}$ Comparing the effects of genocide (columns 1 to 3 of Table 4) with those of civil war (columns 4 to 6) shows that the relative gap in economic performance between areas that have experienced violence and those that have not, tends to be similar for genocide and civil war. ${ }^{46}$ In the first-stage regression of the genocide index, distance to Nyanza has a stronger negative effect than in the general conflict index, confirming that this instrument mainly captures violence against Tutsi.

To assess whether the underlying growth process depends on the type of conflict, we include the interaction effects of the production factors with the genocide and civil war indices, respectively. The results in Table 5 show that, once controlling for endogeneity, the drop in returns to land is much stronger for genocide-related violence than for civil war-related violence, a consequence of the fact that the genocide targeted adult males. ${ }^{47}$ For the same reason, returns to unskilled labor are high and significant in genocide affected areas, while they are not significant in civil war affected areas. This suggests that the reduction in labor supply brought about by the genocide was substantial enough to increase returns to labor, a scenario that resembles the labor market effects of the Black Death in mid-fourteenth-century-United Kingdom and of the HIV epidemic in South Africa mentioned earlier.

The type of conflict also seems to matter for the returns to skilled labor, and this sheds light on the earlier general result. Returns to skilled labor are higher in genocide affected areas but only just significant. In contrast, they are significantly lower in civil war-related areas. This disparity is likely related to the different type of damage but may also stem from the distinct profile of victims associated with each form of violence. Because civil conflict is more likely to destroy factors that augment skilled labor, like, for instance, infrastructure (see Collier 1999), the returns to skilled labor are lower in civil war affected areas. On the other hand, since the genocide targeted the better educated, returns to education in genocide affected areas are higher. These results remain the same when we include migration (not reported).

\section{Robustness Checks}

An empirical study of conflict faces many constraints. We carry out a number of robustness checks to address weaknesses imposed by the data.We first verify 


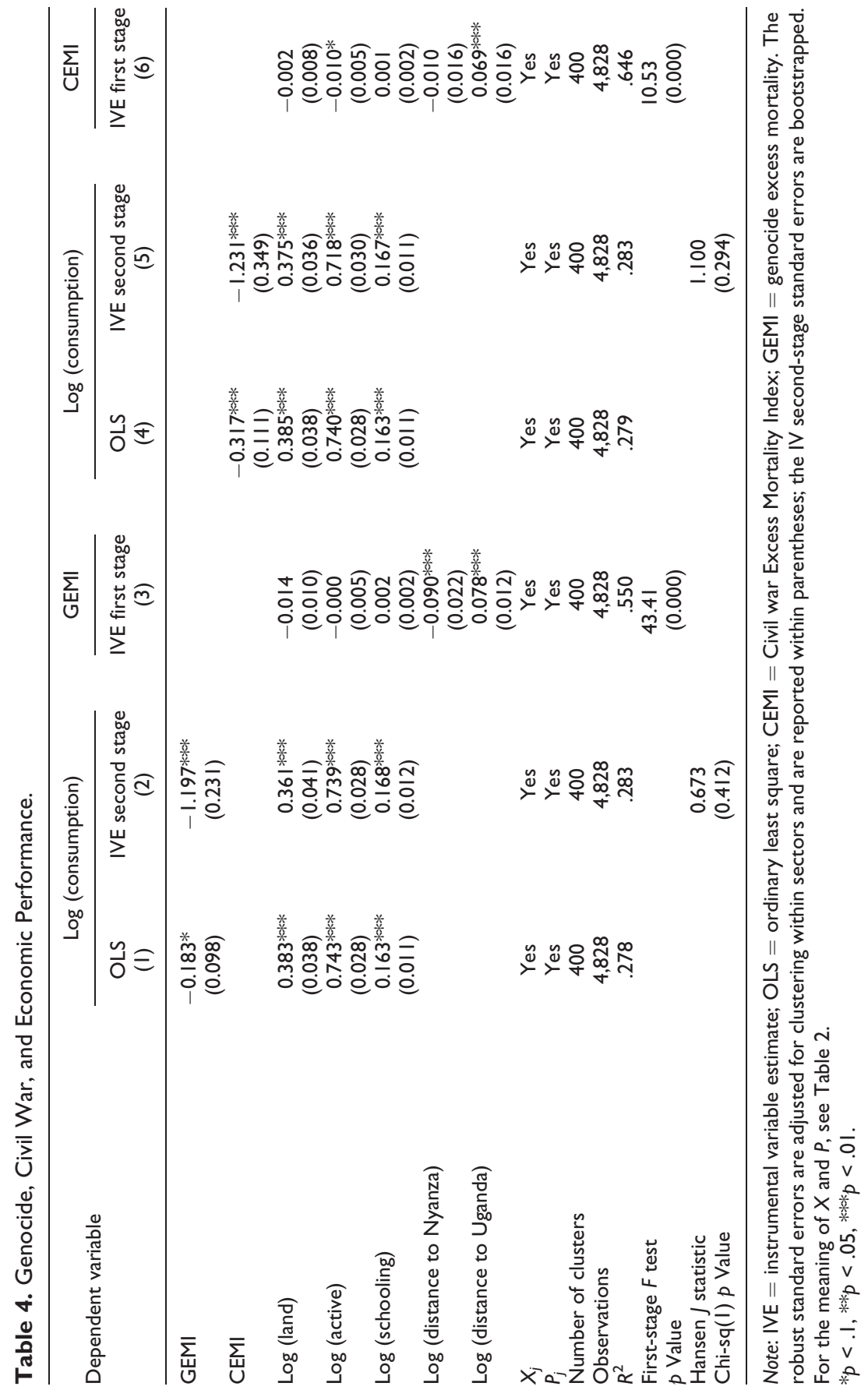


Table 5. Genocide, Civil War, and Economic Performance and Returns to Factors of Production.

\begin{tabular}{|c|c|c|c|c|}
\hline & \multicolumn{4}{|c|}{ Dependent variable: log (consumption) } \\
\hline & $\begin{array}{l}\text { OLS } \\
\text { (I) }\end{array}$ & $\begin{array}{l}\text { IVE second stage } \\
\text { (2) }\end{array}$ & $\begin{array}{l}\text { OLS } \\
(3)\end{array}$ & $\begin{array}{c}\text { IVE second stage } \\
\text { (4) }\end{array}$ \\
\hline GEMI & $\begin{array}{l}-0.537 * * * \\
(0.197)\end{array}$ & $\begin{array}{l}-1.73 I^{* * *} \\
(0.28 I)\end{array}$ & & \\
\hline CEMI & & & $\begin{array}{r}-0.085 \\
(0.205)\end{array}$ & $\begin{array}{l}-1.073^{* * * *} \\
(0.266)\end{array}$ \\
\hline Log (land) & $\begin{array}{l}0.605^{* * *} \\
(0.087)\end{array}$ & $\begin{array}{l}0.732^{* * * *} \\
(0.111)\end{array}$ & $\begin{array}{l}0.575^{* * * *} \\
(0.077)\end{array}$ & $\begin{array}{l}0.428^{* * * *} \\
(0.070)\end{array}$ \\
\hline Log (land) $\times$ GEMI & $\begin{array}{l}-0.600^{* * * *} \\
(0.213)\end{array}$ & $\begin{array}{l}-1.002^{* * * *} \\
(0.27 I)\end{array}$ & & \\
\hline Log $($ land $) \times$ CEMI & & & $\begin{array}{l}-0.579 * * * * \\
(0.201)\end{array}$ & $\begin{array}{c}-0.169 \\
(0.255)\end{array}$ \\
\hline Log (active) & $\begin{array}{l}0.583 * * * \\
(0.064)\end{array}$ & $\begin{array}{l}0.489 * * * \\
(0.088)\end{array}$ & $\begin{array}{l}0.73 I^{* * * *} \\
(0.057)\end{array}$ & $\begin{array}{l}0.801 * * * k \\
(0.061)\end{array}$ \\
\hline Log (active) $\times$ GEMI & $\begin{array}{l}0.419 * * * \\
(0.146)\end{array}$ & $\begin{array}{l}0.659 * * * \\
(0.169)\end{array}$ & & \\
\hline Log $($ active $) \times$ CEMI & & & $\begin{array}{c}0.026 \\
(0.148)\end{array}$ & $\begin{array}{c}-0.239 \\
(0.224)\end{array}$ \\
\hline Log (schooling) & $\begin{array}{l}0.152^{* * * *} \\
(0.023)\end{array}$ & $\begin{array}{l}0.121 * * * \\
(0.027)\end{array}$ & $\begin{array}{l}0.207^{* * * *} \\
(0.023)\end{array}$ & $\begin{array}{l}0.232^{\text {*** }} \\
(0.025)\end{array}$ \\
\hline Log (schooling) $\times$ GEMI & $\begin{array}{c}0.033 \\
(0.055)\end{array}$ & $\begin{array}{l}0.131 * \\
(0.07 I)\end{array}$ & & \\
\hline Log(schooling $) \times$ CEMI & & & $\begin{array}{l}-0.120 * * \\
(0.056)\end{array}$ & $\begin{array}{c}-0.178 * * \\
(0.080)\end{array}$ \\
\hline$X_{j}$ & Yes & Yes & Yes & Yes \\
\hline$P_{j}^{\prime}$ & Yes & Yes & Yes & Yes \\
\hline Number of clusters & 400 & 400 & 400 & 400 \\
\hline Observations & 4,828 & 4,828 & 4,828 & 4,828 \\
\hline$R^{2}$ & .280 & .287 & .281 & .285 \\
\hline
\end{tabular}

Note: IVE = instrumental variable estimate; OLS = ordinary least square; $\mathrm{CEMI}=$ Civil war Excess Mortality Index; GEMI = genocide excess mortality. The robust standard errors are adjusted for clustering within sectors and are reported within parenthese; the IV second-stage standard errors are bootstrapped. For the meaning of $X$ and $P$, see Table 2. For the IV estimates, we follow Wooldridge (2000, Pp. 236-7, cf. also notes in Table 3). The first-stage results are not reported.

$* p<.1, * * p<.05, * * * p<.01$.

whether the estimated equations are well specified. The main issue is whether unobserved heterogeneity is important, as some production factors are omitted from the model. To address this, the model is enriched with the number of livestock, the number of dependents (who may provide additional labor), and whether the household is female headed (having less access to physical labor) ${ }^{48}$ The results remain the same. 
Also, while the analysis has focused on rural areas to address potential heterogeneity in the process of production, the results are very similar when urban areas are included.

Second, we test whether the results remain when using alternative measures of conflict. A possible weakness of the indices used is that they suffer from a potential survival bias, since they are based on population census data from the surviving population and may thus underestimate conflict intensity when the entire households are killed. To address this, alternative indices are constructed, which also include the distance to a mass grave, as the probability that entire families were executed is strongly associated with the proximity to such a site (Verpoorten 2012). ${ }^{49}$

Third, we assess the robustness of our causality identification strategy, first by assessing our instruments, and second by pooling with other data in order to carry out difference-in-difference estimation. While it is accepted that conflict may be endogenous to economic performance, it is also recognized that finding good instruments often remains a challenge. In what is becoming an accepted approach in the conflict literature, ${ }^{50}$ this article uses distance measures as instrumental variables. A potential concern may be that these distances are correlated with the level of economic activity itself. To avoid this, the instruments were made conditional on relevant factors like the distance to the main road, distance to the capital, and land productivity, which are all included as control variables. However, to further address the concern, we carry out a number of inspections. Conley, Hansen, and Rossi (2012) provide a novel way to assess to what extent the exclusion restriction can be relaxed without invalidating the IV results. ${ }^{51}$ Applying their method, we find that the direct effect of the respective instruments on economic performance is allowed to be large, namely +0.28 and -0.11 (for the logarithms of distance to Nyanza and distance to Uganda respectively), before the IV result disappear, providing strong arguments in favour of our instruments. In a further check, the regressions are rerun with an additional control for 1991 baseline wealth as right-hand side variables, proxying for the initial level of economic activity, but the results remain the same. ${ }^{52}$ In another check, the sectors close to the Ugandan border, which may be believed to drive the results because of higher economic performance due to cross border trade, are removed from the analysis. ${ }^{53}$ Again the results remain the same. Together with the Hansen-Sargan test results, this provides strong arguments in favour of the validity of our instruments.

Finally, as an alternative to the instrumental variable estimation, difference-indifference estimation is carried out. If the negative effect of conflict observed above stems from unobserved factors associated with high propensity of conflict, difference-in-difference should produce distinct results. To do this, we pool our 2000 EICV data with the 1990 Rwandan Ministry of Agriculture and Livestock (MINAGRI)/Michigan State University (MSU) agricultural survey, a nationwide survey that took place before the war. These data have a number of shortcomings that prohibit using it for the main analysis. A first constraint is the limited number of observations, namely 84 rural sectors (compared to 405 for the IHLCS data) with very low numbers in some provinces, and a very small overlap across the two 
surveys. ${ }^{54}$ A second shortcoming is that the data contain only information on income and not on consumption, which tends to be smoother and is a better measure for permanent income or welfare. This is especially important in the context of rural Rwanda where farmer's income is strongly related to rainfall, with substantial micro fluctuations and incidences of local famines (see, Verpoorten 2009). A final major shortcoming of the 1990 survey is the sample selection bias, stemming from the fact that the survey only includes land-owning households, excluding the poorest who do not own land.

Because of these limitations, the 1990 data can at best be used to carry out a robustness check. The following difference-in-difference estimation is carried out at the household level:

$$
\begin{aligned}
y_{i}= & \beta_{0}^{\prime \prime}+\beta_{1}^{\prime \prime} C_{i}+\beta_{2} T_{2000 i}+\beta_{3}\left(C_{i} \times T_{2000 i}\right)+A^{\prime \prime \prime} X_{i}+B^{\prime \prime \prime} P_{i} \\
& +D\left(P_{i} \times T_{2000 i}\right)+\varepsilon_{1 i}^{\prime \prime \prime},
\end{aligned}
$$

where $C_{i}$ is the conflict index like before, and $T_{2000 i}$ is a dummy variable taking the value of 1 if the household (or sector) is observed in the postwar 2000 data and 0 otherwise, we test $H_{0}: \beta_{3}=0$. The estimates, presented in Table 6 , confirm our earlier results as the interaction between the conflict index and $T_{2000}$ has a large and negative coefficient (column 1 of Table 6), which is of the same order of magnitude as the earlier IV estimates in Table 2 and becomes extremely similar when controlling for factors of production (column 2 of Table 6). This provides further support for our earlier IV results.

\section{Conclusion}

This article studies the effect of mass killings and human capital destruction on economic performance in Rwanda, using microeconometric analysis. Joining a small body of work that studies the impact of conflict on economic performance within a single country, the analysis differs in four ways from existing work, as it studies the consequences of the destruction of human rather than physical capital, brought about by civil rather than interstate conflict, and considers the economy short after the conflict, namely six years, as opposed to 15-25 years, allowing examination of the ongoing recovery process.

Combining rich household data with unique data on violence in Rwanda, the article finds that households and localities that experienced more intensive conflict lag behind in terms of consumption, relative to those that experienced less intensive conflict. This finding is robust, taking into account the endogeneity of violence, using geographical variables as identifying instruments. It is also robust to controlling for migration.

The result remains when controlling for factors of production, implying that the violence did more than destroying production factors themselves, and also affected the technology, institutions or culture that augment these factors, or the markets 
Table 6. Difference-in-Difference Estimation of the Effect of Conflict on Income.

\begin{tabular}{|c|c|c|}
\hline \multirow[b]{3}{*}{ Dependent variable } & \multicolumn{2}{|c|}{ Household-level estimates } \\
\hline & \multicolumn{2}{|c|}{ Log (income) } \\
\hline & $\begin{array}{l}\text { OLS } \\
\text { (I) }\end{array}$ & $\begin{array}{l}\text { OLS } \\
(2)\end{array}$ \\
\hline WEMI & $\begin{array}{c}0.389 \\
(0.43 \mathrm{I})\end{array}$ & $\begin{array}{c}0.335 \\
(0.358)\end{array}$ \\
\hline y2000 & $\begin{array}{l}0.746 \text { *** } \\
(0.245)\end{array}$ & $\begin{array}{l}0.897^{* * * *} \\
(0.206)\end{array}$ \\
\hline WEMI $\times$ y 2000 & $\begin{array}{c}-0.992 * * \\
(0.495)\end{array}$ & $\begin{array}{c}-0.85 I^{* *} \\
(0.416)\end{array}$ \\
\hline Log (land) & & $\begin{array}{l}0.555^{* * * *} \\
(0.0627)\end{array}$ \\
\hline Log (active) & & $\begin{array}{l}0.814 * * * * \\
(0.0512)\end{array}$ \\
\hline Log (schooling) & & $\begin{array}{l}0.228 * * * * \\
(0.0233)\end{array}$ \\
\hline$X_{j}$ & Yes & yes \\
\hline$P_{j}$ & Yes & yes \\
\hline$P_{j} \times y 2000$ & Yes & yes \\
\hline Number of clusters & 447 & 447 \\
\hline Observations & 5,545 & 5,545 \\
\hline$R^{2}$ & .027 & .127 \\
\hline
\end{tabular}

Note: $\mathrm{OLS}=$ ordinary least square; WEMI $=$ Wartime Excess Mortality Index. The robust standard errors are adjusted for clustering within sectors and are reported within parentheses. For the meaning of $X$ and $P$, see Table 2 .

$*_{p}<.1, *_{p}<.05, * * * p<.01$.

allocating them. This provides further encouragement for research into the social and institutional legacies of conflict, which are still poorly understood. Recent micro-level analysis provides strong evidence that these effects are real but remains inconclusive about the sign of the relationships. ${ }^{55}$

The lower economic performance of areas that have experienced more conflict contrasts with the findings from other studies. The most obvious reason for this difference is that this article looks at economic performance much shorter after the end of conflict, when the economy may be in a phase of post conflict transition. Indeed, when comparing the returns to factors of production between low and high conflict intensity areas using a production function approach, the article finds significantly different returns to land and labor. While the return to land is positive in general, it is almost reduced to zero in past conflict areas, which is consistent with land becoming relatively less scarce in these areas due to excess mortality.

Another potential reason why conflict areas (still) have lower levels of consumption is that it takes an economy longer to recover from human capital destruction 
than from physical capital destruction, as suggested by Barro and Sala-i-Martin (2004).

Distinguishing between genocide, which reflects a brutal destruction of human capital, and civil war, which destroyed less human capital and is associated with higher losses of physical capital, we find distinct effects. Returns to land are lower, and returns to unskilled labor higher for genocide affected areas, more so than for civil war affected areas. This is a direct consequence of the decrease in labor force, as the genocide targeted adult males in particular. In contrast, the returns to skilled labor are lower in civil war affected areas, but not in areas that experienced genocide, which is consistent with civil war bringing more damage to factors that augment skilled labor, although it may also stem from the genocide having targeted the highly educated.

Summarized, these findings provide evidence that recovery depends on the type of violence, providing further encouragement for micro-level analysis of conflict, since these types of findings are hard to obtain from cross-country analysis. The findings also provide lessons for the design of postwar reconstruction policies. Despite the large-scale aid to Rwanda following the 1994 genocide, the most hit areas are still behind. These areas may need more attention but above all a more tailor-made approach that takes into account the type of past conflict.

While considering a relative short period after the conflict as one of the strengths of the data, it also limits the inference that can be drawn. In particular, although we can exclude that a new steady state has been reached, we do not know whether the ongoing process of recovery will end in the prewar steady state, as suggested by neoclassical growth models, or in a new, lower steady state, as implied by poverty trap models. Hence, one direction for future research is a detailed analysis of the time path of recovery. Another research avenue that may prove particularly useful involves assessing the role of factors that have remained unobserved so far, like infrastructure, institutions, and technology. Current and ongoing work in this area is generating new insights into their key role, as discussed above. Future work on other countries will also shed light on how specific the story of Rwanda is and what we can learn for other settings.

\section{Acknowledgments}

We would like to thank Jean-Marie Balland, Francois Bourguignon, Raul Caruso, Giacomo De Luca, Stefan Dercon, Geert Dhaene, Andrea Guariso, Jan Willem Gunning, Romain Houssa, Ana Maria Ibanez, Patricia Justino, Pramila Krishnan, Karen Macours, John McLaren, Oliver Morrison, Elissaios Papyrakis, Jean-Philippe Platteau, Paul Romer, Mans Soderbom, Jo Swinnen and Philip Verwimp for helpful comments, as well as participants at seminars and conferences at the Universities of Amsterdam, Cambridge, Gothenburg, Leuven, Los Andes, Namur, Oxford, Nottingham School of Economics, Paris School of Economics and MIT. We would also like to thank MINAGRI (Rwandan Ministry of Agriculture and Livestock) and USAID, Minnesota Population Centre, the Rwandan National Service of 
Gacaca Jurisdiction, the Rwandan National Census Service and the Rwandan Geographic Information System Centre for making available the data used in this study.

\section{Authors' Note}

Authors can be contacted at p.serneels@uea.ac.uk and marijke.verpoorten@ua.ac.be. The replication files as well as an online appendix to the article can be found at http://jcr.sagepub. com/ and http://www.ua.ac.be/marijke.verpoorten. All errors remain ours.

\section{Declaration of Conflicting Interests}

The authors declared no potential conflicts of interest with respect to the research, authorship, and/or publication of this article.

\section{Funding}

The authors received no financial support for the research, authorship, and/or publication of this article.

\section{Notes}

1. For an overview, see Blattman and Miguel (2010).

2. See also Djankov and Reynal-Querol (2010) work on poverty and civil war.

3. In political science, the process of catch-up is sometimes referred to as "The Phoenix Factor," as described in Organski and Kugler (1977), and the focus is on analyzing political and community processes underlying catch-up (see, for instance Kugler and Arbetman 1989; Flores and Nooruddin 2009). In this article, we abstract from political processes.

4. Cederman and Gleditsch (2009) for instance show how "disaggregating civil war" can yield new insights into the causes of conflicts. Daly (2012), using micro data, casts doubt on conventional Correlates of War, while Bohora, Mitchell, and Nepal (2006) show the importance of subnational geography to understanding conflict in Nepal. Blattman (2009) using micro data finds that exposure to violence can lead to increased political participation and argues that this cannot readily be explained using established theory. Humphreys and Weinstein (2006) report significant variation in the extent to which warring groups abuse civilians across groups, geography, time, and conflict.

5. See for instance Pierskalla (2010) for the effects of repression on dissent, and Herreros (2006) for its possible effectiveness; Davenport (1996) for the effects of democracy, coercive capacity, and political conflict on repressive behavior; and Einolf (2007) on torture. See later in this section for micro-level evidence on the political and social consequences of conflict.

6. A comparison with economic consequences of similar large shocks, like natural disasters, is intuitively appealing but seems less relevant, given the fundamentally different nature, because of the reverse causality between conflict and growth that tends to exacerbate the effects. In contrast, the growth effects of natural disaster seems limited, as economies have no inevitable reduction in either short or long run growth and seem to be quite resilient to natural disaster (see Bevan 2011). 
7. This is a general form of the model presented in Romer (2006) and can be seen as a generalization of Arrow (1962), Mankiw, Romer, and Weil (1992), or Lucas (1988). Studies investigating the effect of conflict add the latter as a right-hand side variable.

8. For a detailed discussion, see Blattman and Miguel (2010) who also mention vintage capital models that are less relevant to our case.

9. The argument goes that the effect of peace depends on whether the economy has already adapted to the new situation, for example, by adjusting investment rates when taking increased insecurity and risk into account. If the country has not adapted yet (e.g., during a short war), the economy will continue to have lower growth (adjust its investment rates downward), while if it has adapted (e.g., during a long war), it will have higher growth.

10. For a discussion of the reverse relationship, see Collier and Hoeffler (1998). Miguel, Satyanath, and Sergenti (2004) also estimate the effect of economic factors on the likelihood of civil conflict using a convincing identification strategy.

11. Research on terrorism provides exceptions. Blomberg, Hess, and Orphanides (2004) using a structural VAR model estimate the impact of terrorism on economic performance applying instrumental variable/generalized method of moments estimation to panel data across 177 countries. Gaibulloev and Sandler (2008) present panel estimates for eighteen Western Europe countries and observe a negative relationship between transnational terrorism and income per capita growth for 1971-2004, suggesting that each additional transnational terrorist incident per million persons reduces economic growth by about .4 percent points, while domestic terrorism has a much smaller effect about half this size. In a follow-up study (2009), the same authors find similar effects for Asia, suggesting that an additional terrorist incident per million persons reduces gross domestic product per capita growth by about 1.5 percent, although these results reflect association rather than causation.

12. Chen, Loayza, and Reynal-Querol (2008) address some of these issues comparing before and after outcomes with a control group of countries that are similar except for the conflict.

13. Bellows and Miguel (2006, 2009), for instance, find that war victimization increases later individual political participation in Sierra Leone, while Blattman (2009) finds former combatants in Uganda to be more likely to vote and become local leaders. Carmil and Breznitz (1991) confirm that exposure can lead to greater political activism among groups such as Jewish Holocaust survivors, and this is confirmed for Palestinian bombardment victims by Punamäki, Quota, and El Sarraj (1997). Further recent work illustrates how norms, attitudes, and political culture can be altered. Paluck and Green (2009) reporting on the results from an experimental radio intervention in postgenocide Rwanda find that while the radio program had little effect on many kinds of beliefs and attitudes, it had a substantial impact on listeners' willingness to express dissent and the ways they resolved communal problems. Nelson, Clawson, and Oxley (1997) show that how violence is framed is important, reporting on two experiments that examined the effect of news frames on tolerance for the Ku Klux Klan. Fearon, Humphreys, and Weinstein (2009) illustrate how development aid can contribute to social cohesion after civil war using a field experiment in Sierra Leone, and in follow-up work Fearon, Humphreys, and Weinstein (2011) find that the effects of community-driven development interventions on 
cooperation while overall positive are also heterogeneous suggesting that they depend on the nature of collective action problems that local communities face.

14. Two other article carry out a micro-level analysis. Vothknecht and Sumarto (2011) carry out a district-level analysis and disentangle the overall negative association between growth and violence into sectoral components, observing substantial differences across sectors, with the most detrimental impact evident in manufacturing industries and the service sectors. Construction seem to recover soon after conflict ends, while manufacturing and finance appear more reliant on lasting peace. Since the analysis does not address endogeneity, no causal inference can be drawn. Bohlken and Sergenti (2010) study the reverse relationship and using IV estimation find that a one percentage point increase in economic growth decreased the expected number of riots between Hindu and Muslim by over 5 percent.

15. We use "human capital" in its broadest sense, referring to the qualities that allow people to perform labor, including "being alive," but also the level of education completed.

16. More recent work concentrates on the increase in nominal wages, as new evidence suggests that rising food prices resulting in high inflation may have neutralised a rise in real wages (see Munro 2004).

17. For evidence on the effects of conflict on fertility, see de Walque (2004) who observes that fertility and marriage rates in Cambodia were very low under the Khmer Rouge but bounced back after the regime collapsed, and Shemyakina (2011) finds that conflict made young women in Tajikistan marry either earlier or later and had children earlier.

18. The Rwanda Patriotic Front (RPF), an army built up by refugees from Rwanda's previous conflicts living in Uganda, invaded Rwanda from the North at the end of 1990 and this led to intermittent hostilities and negotiations with the Rwandan government until a peace agreement was reached in 1993.

19. Genocide has a particular standing both in conflict theoretical and in legal terms. It distinguishes itself from other types of conflict in victims being killed for reasons associated with their mere existence that cannot be changed simply (e.g., belonging to a certain ethnicity or social group) and has important legal implications, for instance, the obligation to intervene for the international community.

20. Davenport and Stam (2009) provide a micro-level analysis of the Rwanda conflict on the political dimensions. Structured quantitative studies of genocide remain rare, and where available focus on cross-country evidence; see for instance the excellent study by Harff (2003).

21. Comparison of different types of conflict in very different areas (or periods) is bound to be contaminated by unobserved differences; these are very limited when comparing distinct types of conflicts at the same time in the same area.

22. See Gleditsch et al. (2002); Sambanis (2001); Kalyvas (2007) and Balcells and Kalyvas (2010), respectively.

23. It has been argued that the focus on micro-level dynamics, while increasing internal validity, sacrifices external validity (see, for instance, Kalyvas 2008); others believe that any comparison across conflicts is futile (see, for example, Prunier 2010). Our analysis focuses on economic processes following a rich tradition in micro economic research that uses systematic comparison anchored in theory to generate new insights. 
24. See de Walque and Verwimp (2010)

25. Justino and Verwimp (2006) present rank correlations at the province level between preconflict (1990) income, 1990-2000 growth, and changes in labor-capital ratios, and use province-level event data to interpret observed patterns.

26. This is further of interest because the recurrent violence in Rwanda's history has been explained in terms of the relative small amount of land available for households in rural areas (André and Platteau 1998).

27. The battle front then moved to other areas of the country, safeguarding the remaining Tutsi from being killed and engaging in reprisal killings on Hutu who allegedly participated in the genocide (Davenport and Stam 2009).

28. Other work uses similar identifying instruments for conflict, including Miguel and Roland (2011) who use the historic border between North and South Vietnam; and Akresh and de Walque (2008) who, in their study on schooling in Rwanda, also use the distance to Uganda, but at the level of the eleven provinces. Here we make use of more detailed spatial data, containing the distance of each of the 139 rural communes to Uganda.

29. Nyanza is located in the North-Western corner of Butare, a southern province, more specifically at the cross section of the provinces Butare, Gitarama, and Gikongoro. Its power was further weakened by a reorganization of Rwanda's administrative division shortly after independence, when the southern and western outskirts of Nyanza were attached to eastern Gikongoro, a highland area inhabited largely by Hutu, with the aim of further weakening Tutsi influence around the former royal capital (Besforges, 1999).

30. See also Blattman and Miguel (2010) for a detailed discussion on this.

31. Areas where surplus labor has been reduced may now yield relatively higher ret Forges labor and therefore attract migrant labor and resettlers. This may also affect the returns to land, bring new technologies, and affect existing institutions. While the role of migration is interesting in itself, it is also complicated and requires a separate in-depth analysis. Here we limit ourselves to investigating whether our results are robust to controlling for migration.

32. Enquête Intégrée sur les Conditions de Vie des ménages/Integrated Household Living Conditions Survey.

33. The sector corresponds to the smallest codified Rwandan administrative unit. At the time of the genocide, Rwanda was divided into 10 prefectures, 145 communes (of which 6 entirely urban), and 1,565 sectors. The first administrative reform (1996) replaced the ten prefectures by twelve provinces, adding Kigali City and Umutara. The second administrative reform (2002) replaced the 145 communes by 30 districts and the 12 provinces by 5 regions. On average, a sector counts 5,000 inhabitants, while a commune counts 50,000 inhabitants.

34. Figure A.1 in the online appendix plots a kernel density for the logarithm of household expenditures

35. Using a 2,000 exchange rate of 393 Rwandan franc (RWF)/US\$. 
36. All results are very similar if we use per capita consumption instead of household consumption, if we use land cultivated instead of land owned, or if we use other measures of education (see robustness checks).

37. Developing these indices follows a long-standing demographic tradition to infer excess mortality from characteristics of the surviving population, a method referred to as indirect mortality estimation (Hill and Trussel 1977; Timaeus 1986). Because obtaining absolute numbers of excess mortality is extremely demanding in terms of data requirements (as well as assumptions), the present method focuses on capturing relative excess mortality and its spatial distribution.

38. More accurately, principal component 2 captures the intensity of other-than-genociderelated excess mortality. The denomination "civil war" is a simplification made for ease of exposure but captures the key dimension in this context, as is clear from the discussion in the third section.

39. This is confirmed by their kernel density plots in Appendix Figure A2a-A2b.

40. Annual long-term average precipitation and altitude are calculated for all administrative sectors based on information of a subsample of sectors (taken from the Direction des Statistiques Agricoles) and a distance-based spatial weighting procedure run in GeoDa (Anselin 1995).

41. Population density is a classic proxy for land productivity in Rwanda because the most fertile areas are the most densely populated ones. In some cases, this is, however, ambiguous because, by 1970 , population density had become so high in certain areas that even marginal lands were being cultivated and land conflict became very frequent, putting a strain on land productivity (André and Platteau 1998). As a consequence of the lack of land in the fertile western highlands, migrants were encouraged to settle in areas with lower soil fertility, especially in the East of the country. In a disaggregated spatial analysis of demographic trends in Rwanda during the period 1978-1991, Olson (1994) convincingly demonstrates that areas with infertile soils experienced the highest population growth. Hence, to further distinguish differences in soil fertility among the high populated ones, we use population growth between 1978 and 1991 using the census data for these years.

42. See also Davenport and Stam (2009) on the sequencing of genocide and the advancement of the RPF.

43. The standard errors only change marginally and the results remain qualitatively the same.

44. Estimates vary, with a maximum of up to 2 million internally and externally displaced. Most people fled to neighboring countries. This is consistent with the recent findings on migration and violence, which indicate that, in contrast with common perception in Organization for Economic Cooperation and Development countries, refugees typically end up in countries close by, even if these are also at war, as well as in places with other diaspora (see, Moore and Shellman 2007). Iqbal (2007) also confirms proximity as one of the key variables explaining refugees' migration behavior. Most of the externally displaced resettled in Rwandan in the course of 1997-1998. Rwandans who lived in exile prior to the genocide also returned to their country of origin after the genocide (Prunier 1998). 
45. The Genocide Excess Mortality Index ([GEMI]; Civil War Excess Mortality Index [CEMI] effect reflects how genocide (civil war) affected areas perform relative to nongenocide (civil war) affected areas. Because the two violence-specific indices are orthogonal by construction, their coefficients can become larger than those of the compact index.

46. To address the concern that the civil war effect reflects the effects of post-1994 (counter) insurgencies, we carry out a robustness test by excluding the two provinces where these insurgencies were concentrated, namely Gisenyi and Ruhengeri, and find that the results remain very similar (not reported).

47. The reason is that land and unskilled labor are complements, the amount of land per household is fixed (as there is almost no selling of land, sales) and there is limited hiring of labor (possibly due to cash constraints or market failures). Note that the drop in unskilled labor was substantial, representing 12 percent of the active population. An additional reason for the strong negative land effects is gender related. Violence targeted mostly men and this resulted in many of the remaining households being female headed (32 percent). These households are likely to have lower returns to land not only because they have less labor but also because women traditionally do not carry out certain tasks (see Schindler 2010), and because women's property rights are less secure (see also Ayelew, Deininger, and Goldstein 2011), which is likely to lead to lower investment (and lower use of complementary inputs, like fertilizer).

48. Livestock ownership is measured by the log of tropical livestock units owned. The number of dependent household members is measured as the log of members aged younger than fifteen or older than sixty-five. Using an alternative method to control for heterogeneity of household size, that is, using per capita household consumption as a dependent variable also yields similar results.

49. The distance to a mass grave is calculated at the commune level using information from the Yale Genocide Studies on the location of seventy-one mass graves (see http://www. yale.edu/gsp).

50. See for instance Miguel and Roland (2011) and Akresh and de Walque (2008).

51. Simulations are available upon request. The method exists of regressing the difference between the dependent variable and the iv on the predicted endogenous variable obtained from the first stage $(Y-m Z=a+b(p X))$, and then increase the weight of the iv $(m)$ until the coefficient on the predicted endogenous variable $(b)$ reaches zero to conclude that the direct effect of the iv needs to be as large as $m$ in order to yield a significant effect while the actual effect is zero.

52. We use the commune average of assets owned and the commune average of the years of schooling of the active population (15-65). These variables are calculated from the 1991 population census. The asset variable is constructed as the simple sum of indicator variables for ownership of high-value assets.

53. We use $20 \mathrm{~km}$ as the break off point, but the results are similar when using alternative distances.

54. Only twenty-five sectors are present in both surveys. The data also have no panel dimension at the household level. 
55. Presented in a stylised way, one view argues that conflict can be "a midwife" for cherished institutions like democracy, rule of law, aversion of injustice, and so on (see for instance Weber 1965; Tilly 1982; Blattman and Miguel 2010; Bowles 2012; as well as the recent "Give war a chance" literature Luttwak 1999; Herbst 2000); another view argues that conflict can be detrimental to institutions (see for instance Thies 2005; Blattman and Miguel 2010). Recent emerging micro-level research provides new but inconclusive evidence (see for instance Bellows and Miguel 2008; Voors et al. 2012 for micro-evidence supporting the first view, while Chaux 2009 ahd Miguel, Saiegh, and Satyanath 2008 for evidence in support of the second view).

\section{Supplemental Material}

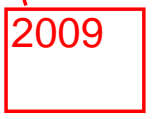

The online appendices are available at http://jcr.sagepub.com/supplemental.

\section{References}

Akresh, R., and D. de Walque. 2008. "Armed Conflict and Schooling: Evidence from the 1994 Rwandan Genocide." IZA Discussion Papers 3516, Institute for the Study of Labor (IZA), HiCN Working Papers, 47.

Akresh, R., P. Verwimp, and T. Bundervoet. 2011. "Civil War, Crop Failure, and Child Stunting in Rwanda." Economic Development and Cultural Change 59:777-810.

Alderman, H., J. Hoddinott, and B. Kinsey. 2006. "Long Term Consequences of Early Childhood Malnutrition." Oxford Economic Papers 58:450-74.

André, C., and J. P. Platteau. 1998. "Land Relations Under Unbearable Stress: Rwanda Caught in the Malthusian Trap." Journal of Economic Behavior and Organization 34:1-47.

Anselin, L. 1995. "Local Indicators of Spatial Association."Geographical Analysis 27: 93-115. Arcand J., and E. D. Wouabe. 2009. Households in a Time of War: Instrumental Variables Evidence for Angola. Working paper. The Graduate Institute, Geneva.

Arrow, K. J. 1962. “The Economic Implications of Learning by Doing." Review of Economic Studies 29:155-73.

Ayelew, D. A., K. Deininger, and M. Goldstein. 2011. "Environmental and Gender Impacts of Land Tenure Regularization in Africa." Pilot Evidence from Rwanda. Policy Research Working Paper 5765. The World Bank, Development Research Group, Agriculture and Rural Development Team, and Africa Region Gender Team.

Azariadis, C., and A. Drazen. 1990. "Threshold Externalities in Economic Development." Quarterly Journal of Economics 105:501-26.

Balcells, L., and S. N. Kalyvas. 2010. "Did Marxism Make a Difference?" Marxist Rebellions and National Liberation Movements, mimeo prepared for the Annual Meeting of the American Political Science Association, Washington DC.

Barro, J., and X. Sala-i-Martin. 2004. Economic Growth, 2nd edition. Cambridge, MA: MIT Press, Second Edition.

Bellows, J., and E. Miguel. 2006. "War and Institutions: New Evidence from Sierra Leone." American Economic Review 96:394-99.

Bellows, J., and E. Miguel. 2009. "War and Local Collective Action in Sierra Leone." Journal of Public Economics 93:144-57. 
Bevan, D. L. 2011. The Economic Growth Impacts of Extreme Events, St John's College, Oxford. Paper prepared for the UK Government Office for Science 's Foresight Project, Migration and Global Environmental Change.

Blattman, C. 2009. "From Violence to Voting: War and Political Participation in Uganda." American Political Science Review 103:231-47.

Blattman, C., and J. Annan. 2010. "The Consequences of Child Soldiering." The Review of Economics and Statistics 92:882-98.

Blattman, C., and E. Miguel. 2010. "Civil War." Journal of Economic Literature 48:3-57.

Brakman, S., H. Garretsen, and M. Schramm. 2004. "The Strategic Bombing of Cities in Germany in World War II and its Impact on City Growth." Journal of Economic Geography 4: $1-18$.

Blomberg, S. B., G. D. Hess, and A. Orphanide. 2004. "The Macroeconomic Consequences of Terrorism." Journal of Monetary Economics 51:1007-32.

Bohlken, A. T., and E. J. Sergenti. 2010. "Economic Growth and Ethnic Violence: An Empirical Investigation of Hindu-Muslim Riots in India." Journal of Peace Research 47:589-600.

Bohora, A. K., N. J. Mitchell, and M. Nepal. 2006. "Opportunity, Democracy, and the Exchange of Political Violence: A Subnational Analysis of Conflict in Nepal." Journal of Conflict Resolution 50:108.

Bundervoet, T., P. Verwimp, and R. Akresh. 2009. "Health and Civil War in Rural Burundi." Journal of Human Resources 44:536-63.

Bureau of Intelligence and Research. 1965. Zaire, Congo (Leopoldville)]-Rwanda Boundary. International Boundary study No. 52, The Geographer, Office of the Geographer.

Carmil, D., and S. Breznitz. 1991. "Personal Trauma and World View-Are Extremely Stressful Experiences Related to Political Attitudes, Religious Beliefs, and Future Orientation?" Journal of Traumatic Stress 4:393-405.

Cederman, L.-E., and K. S. Gleditsch. 2009. "Introduction to Special Issue on "Disaggregating Civil War." Journal of Conflict Resolution 53:487-99.

Chamarbagwala, R., and H. E. Morán. 2011. "The Human Capital Consequences of Civil War: Evidence from Guatemala." Journal of Development Economics 94:41-61.

Chaux, E. 2009. "Citizenship Competencies in the Midst of a Violent Political Conflict: The Colombian Educational Response." Harvard Educational Review 79:84-93.

Chen, S., N. V. Loayza, and M. Reynal-Querol. 2008. "The Aftermath of Civil War." World Bank Economic Review 22:63-85.

Cerra, V., and S. C. Saxena. 2008. "Growth Dynamics: The Myth of Economic Recovery." American Economic Review 98:439-57.

Collier, P. 1999. "On the Economic Consequences of Civil War." Oxford Economic Papers $51: 168-83$.

Collier, P., and A. Hoeffler. 1998. "On Economic Causes of Civil War." Oxford Economic Papers 50:563-73.

Conley, T., C. Hansen, and P. E. Rossi. 2012. "Plausibly Exogenous." Review of Economics and Statistics 94:260-72. 
Daly, S. Z. 2012. “Organizational Legacies of Violence: Conditions Favoring Insurgency Onset in Colombia, 1964-1984." Journal of Peace Research 49:473-85.

Davenport, C. 1996. "The Weight of the Past: Exploring Lagged Determinants of Political Repression." Political Research Quarterly 49:377-403.

Davenport, C., and A. Stam. 2009. Rwandan Political Violence in Space and Time, Unpublished manuscript.

Davis, D. R., and D. E. Weinstein. 2002. "Bones, Bombs, and Break Points: The Geography of Economic Activity." American Economic Review 92:1269-89.

de Walque, D. 2004. The long-term legacy of the Khmer Rouge period in Cambodia. Policy Research Working Paper Series 3446. Washington, DC : World Bank, Development Research Group.

de Walque, D., and P. Verwimp. 2010. "The Demographic and Socio-economic Distribution of Excess Mortality During the 1994 Genocide in Rwanda." Journal of African Economies 19:141-62.

Des Forges, A. 1999. Leave None to Tell the Story: Genocide in Rwanda. New York: Human Rights Watch.

Djankov, S., and M. Reynal-Querol. 2010. "Poverty and Civil War: Revisiting the Evidence." Review of Economics and Statistics 92:1035-41.

Einolf, C. J. 2007. "The Fall and Rise of Torture: A Comparative and Historical Analysis." Sociological Theory 25:101-21.

Farmer, D. L. 1991. "Prices and Wages, 1350-1500." In The Agrarian History of England and Wales, Vol. III, edited by E. Miller, 431-94. Cambridge: Cambridge University Press.

Fearon, J. D., M. Humphreys, and J. M. Weinstein. 2009. “Can Development Aid Contribute to Social Cohesion after Civil War? Evidence from a Field Experiment in Post-Conflict Liberia." American Economic Review: Papers \& Proceedings 99:287-91.

Fearon, J., M. Humphreys, and J. Weinstein. 2011. Democratic Institutions and Collective Action Capacity, mimeo. : Results from a Field Experiment in Post-Conflict Liberia. Presented at the 2011 Annual Meetings of the American Political Science Association, Seattle, WA, September 1-4, 2011.

Flores, T. E., and I. Nooruddin. 2009. "Democracy Under the Gun: Understanding Post-Conflict Recovery." Journal of Conflict Resolution 53:3-29.

Gaibulloev, K., and T. Sandler. 2008. "Growth Consequences of Terrorism in Western Europe." Kyklos 61:411-24.

Gleditsch, N. P., P. Wallensteen, M. Eriksson, M. Sollenberg, and H. Strand. 2002. “Armed Conflict 1946-2001: A New Dataset.” Journal of Peace Research 39:615-37.

González, M. A., and R. A. Lopez. 2007. "Political Violence and Farm Household Efficiency in Colombia." Economic Development and Cultural Change 55:367-92.

Government of Rwanda. 2002. Recensement Général de la Population et de l'Habitat Rwanda: 16-30 Aout 2002. Kigali, Rwanda: Service National de Recensement.

Herbst, Jeffrey. 2000. States and Power in Africa: Comparative Lessons in Authority and Control. Princeton, NJ: Princeton University Press.

Herreros. 2006. "'The Full Weight of the State': The Logic of Random State-Sanctioned Violence." Journal of Peace Research 43:671-89. 
Hibbs, D. 1973. Mass Political Violence: A Cross-national Causal Analysis. Hoboken, NJ: John Wiley \& Sons.

Hill, K., and T. Trussell. 1977. "Further Developments in Indirect Mortality Estimation." Population Studies 31:75-84.

Humphreys, M., and J. M. Weinstein. 2006. "Handling and Manhandling Civilians in Civil War: Determinants of the Strategies of Warring Factions." American Political Science Review 100: 429-47.

Iqbal, Z. 2007. "The Geo-Politics of Forced Migration in Africa, 1992-2001." Conflict Management and Peace Science 24:105.

Justino, P. 2007. On the Links between Violent Conflict and Household Poverty: How Much Do We Really Know? MICROCON Research Working Paper 1. Patricia Justino: University of Sussex.

Justino, P., and P. Verwimp. 2006. Poverty Dynamics, Violent Conflict and Convergence in Rwanda. HiCN Working Papers 16. Berlin, Rwanda: Households in Conflict Network.

Kalyvas, S. N. 2007. "Civil Wars." In The Oxford Handbook of Comparative Politics, edited by Carles Boix and Susan C. Stokes, 416-34. Oxford, UK: Oxford University Press.

Kalyvas, S. N. 2008. "Promises and Pitfalls of an Emerging Research Program: The Microdynamics of Civil War." In Order, Conflict, Violence, edited by S. N. Kalyvas, I. Shapiro, and T. Masoud, 397-421. Cambridge: Cambridge University Press.

Kugler, J., and M. Arbetman. 1989. "Exploring the Phoenix Factor with the Collective Goods Perspective." Journal of Conflict Resolution 33:84-112

Lopez, H., and Q. Wodon. 2005. "The Economic Impact of Armed Conflict in Rwanda." Journal of African Economies 14:586-602.

Lucas, R. E. 1988. "On the Mechanics of Economic Development." Journal of Monetary Economics 22:3-42.

Luttwak, E. N. 1999. "Give War a Chance." Foreign Affairs 78:36-44.

Mankiw, N. G., D. Romer, and D. N. Weil. 1992. "A Contribution to the Empirics of Economic Growth." Quarterly Journal of Economics 107:407-37

McKay, A., and S. Loveridge. 2005. Exploring the Paradox of Rwandan Agricultural Household Income and Nutritional Outcomes in 1990 and 2002, Staff Paper 2005-6, MSU, Michigan: Department of Agricultural, Food, and Resource Economics.

Miguel, E., and G. Roland. 2011. "The Long Run Impact of Bombing Vietnam.” Journal of Development Economics 96:1-15.

Miguel, E., S. M. Saiegh, and S. Satyanath. 2008. National Cultures and Soccer Violence. National Bureau of Economic Research Working Paper 13968. National Bureau of Economic Research, Inc.

Miguel, E., S. Satyanath, and E. Sergenti. 2004. "Economic Shocks and Civil Conflict: An Instrumental Variables Approach." Journal of Political Economy 112:725-53.

Moore, W. H., and S. M. Shellman. 2007. "Whither Will They Go? A Global Study of Refugees' Destinations, 1965-1995.” International Studies Quarterly 51:811-34. 
Munro, J. 2004. Before and After the Black Death: Money, Prices, and Wages in FourteenthCentury England. WORKING PAPER No. 24, UT-ECIPA-MUNRO-04-04, Department of Economics and Institute for Policy Analysis, University of Toronto.

Murdoch, J. C., and T. Sandler. 2004. "Civil Wars and Economic Growth: Spatial Dispersion." American Journal of Political Science 48:138-51.

Nelson, T. E., Rosalee A. Clawson, and Zoe M. Oxley. 1997. "Media Framing of a Civil Liberties Conflict and Its Effect on Tolerance." American Political Science Review 91: 567-83.

Olson, J. M. 1994. "Demographic Responses to Resource Constraints in Rwanda, Rwanda Society-Environment Project." Working Paper 7, Department of Geography and the Centre of Advanced Study of International Development, MSU.

Organski, A. F. K., and J. Kugler. 1977. "The Costs of Major Wars: The Phoenix Factor.” The American Political Science Review 71:1347-66.

Paluck, E. L., and D. P. Green. 2009. "Deference, Dissent, and Dispute Resolution: An Experimental Intervention Using Mass Media to Change Norms and Behavior in Rwanda." American Political Science Review 103:622-44.

Pierskalla, J. H. Protest. 2010. "Deterrence, and Escalation: The Strategic Calculus of Government Repression." Journal of Conflict Resolution 54:117.

Prunier, G. 1998. "The Rwanda Crisis." History of a Genocide, 424. NewYork: Columbia University Press.

Prunier, G. 2010. "Rwanda and Darfur: A Comparative Approach to Two Peacekeeping Failures." Journal of Peacekeeping 14:117-33.

Punamäki, R. -L., S. Qouta, and E. El Sarraj. 1997. "Relationships between Traumatic Events, Children's Gender, and Political Activity, and Perceptions of Parenting Styles." International Journal of Behavioral Development 21:91-109.

Rodrik, D. 1999. "Where Did All the Growth Go? External Shocks, Social Conflict, and Growth Collapses." Journal of Economic Growth 4:385-412.

Romer, D. 2006. Advanced Macroeconomics. NewYork: McGraw Hill.

Sachs, J. D. 2005. The End of Poverty: Economic Possibilities for Our Time. New York: The Penguin Press.

Sambanis, N. 2001. "Do Ethnic and Nonethnic Civil Wars Have the Same Causes?: A Theoretical and Empirical Inquiry (Part 1)." Journal of Conflict Resolution 45:259-82.

Schindler, K. 2010. "Who Does What in a Household After Genocide?" Evidence from Rwanda. HiCN Working Paper 90. Households in Conflict Network.

Shemyakina, O. 2011. "The Effect of Armed Conflict on Accumulation of Schooling: Results from Tajikistan." Journal of Development Economics 95:186-200.

Thies, C. G. 2005. "War, Rivalry, and State Building in Latin America." American Journal of Political Science 49:451-65.

Tilly, C. 1982. Warmaking and Statemaking as Organized Crime. University of Michigan Center for Research on Social Organizations. Working Paper 256.

Timaeus, I. M. 1986. "Estimation of Mortality from Orphanhood in Adulthood." Demography. 28:213-27. 
UNHCR (United Nations High Commissioner for Refugees). 2000. The State of the World's Refugees 2000: Fifty Years of Humanitarian Action. Chapter 10: The Rwandan genocide and its aftermath. Oxford, UK: Oxford University Press.

Venieris, Y., and D. Gupta. 1986. "Income Distribution and Socio-political Instability as Determinants of Savings: A Cross-sectional Model." Journal of Political Economy 96: 873-83.

Verpoorten, M. 2009. "Cattle Sales in War and Peacetime: A Study of Household Coping in Rwanda, 1991-2001.” Journal of Development Economics 88:67-86.

Verpoorten, M. 2011. "Measure for Measure: How Well Do We Measure Micro-level Conflict Intensity." LICOS Discussion Paper nr. 275.

Verpoorten, M. 2012. "Detecting Hidden Violence: The Spatial Distribution of Excess Mortality in Rwanda." Political Geography 31:44-56.

Verpoorten, M., and L. Berlage. 2007. "Economic Mobility in Rural Rwanda: A Study of the Long Term Effects of War and Genocide at the Household Level." Journal of African Economies 16:1-44.

Vothknecht, M., and S. Sumarto. 2011. "Beyond the Overall Economic Downturn: Evidence on Sector-specific Effects of Violent Conflict from Indonesia.” DIW Berlin Discussion Paper 1105.

Weber, Max. 1965. Politics as a Vocation. Minneapolis, MN: Fortress Press.

Wooldridge, J. 2000. Econometric Analysis of Cross Section and Panel Data. Cambridge, MA: MIT Press.

Young, A. 2005. "The Gift of Dying: The Tragedy of Aids and the Welfare of Future African Generations." Quarterly Journal of Economics 120:423-66. 